Chapter 9: Climate Variability and Weather Extremes: Model-Simulated and Historical Data

\author{
Siegfried D. Schubert and Young-Kwon Lim ${ }^{1}$ \\ Global Modeling and Assimilation Office, NASA/GSFC
}

Greenbelt, MD 20771

$9.1 \quad$ Introduction.................................................... 2

9.2 Observed and Simulated Climate variability and Weather Extremes

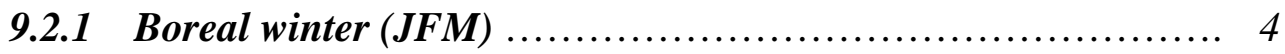

9.2.1.1 Climatology and Variability............................ 5

9.2.1.2 Regional Impacts of Climate Variability................. 9

9.2.1.3 Long-Term (Decadal-Scale) Changes.................... 11

9.2.2 Austral Winter (JAS) ................................... 16

9.2.2.1 Climatology and Variability.......................... 16

9.2.2.2 Regional Impacts of Climate Variability................. 20

9.2.2.3 Long-Term (Decadal-Scale) Changes.................. 20

\title{
9.3 Impact of $\mathrm{CO}_{2}$ Doubling and Uniform SST Increase
}

9.3.1 Boreal winter (JFM) .................................... 25

9.3.1.1 Impact on the Mean Climate and Weather Variability...... 25

9.3.1.2 Impact on Climate Variability......................... 27

9.3.2 Austral winter (JAS) .................................... 29

9.3.2.1 Impact on Mean Climate and Weather Variability.......... 29

9.3.2.2 Impact on Climate Variability.............................. 32

$9.4 \quad$ Summary and Discussion......................................... 33

\section{Appendix A}

The GEOS-5 Model and Experiments ............................... 38

MERRA and Other Observations.................................. 40

\section{Appendix B}

Some examples of fits to the GEV distribution....................... 41

References................................................................. 42

\footnotetext{
${ }^{1}$ Also, Goddard Earth Sciences Technology and Research (GESTAR), 8800 Greenbelt Rd., Greenbelt, MD 20771
} 


\subsection{Introduction}

Extremes in weather and climate encompass a wide array of phenomena including tropical storms, mesoscale convective systems, snowstorms, floods, heat waves, and drought. Understanding how such extremes might change in the future requires an understanding of their past behavior including their connections to large-scale climate variability and trends.

Previous studies suggest that the most robust findings concerning changes in short-term extremes are those that can be most directly (though not completely) tied to the increase in the global mean temperatures. These include the findings that (IPCC 2007): "There has been a widespread reduction in the number of frost days in mid-latitude regions in recent decades, an increase in the number of warm extremes, particularly warm nights, and a reduction in the number of cold extremes, particularly cold nights.” For North America in particular (CCSP SAP 3.3, 2008): "There are fewer unusually cold days during the last few decades. The last 10 years have seen a lower number of severe cold waves than for any other 10-year period in the historical record that dates back to 1895 . There has been a decrease in the number of frost days and a lengthening of the frost-free season, particularly in the western part of North America."

Other aspects of extremes such as the changes in storminess have a less clear signature of long term change, with considerable interannual, and decadal variability that can obscure any climate change signal. Nevertheless, regarding extratropical storms (CCSP SAP 3.3, 2008): "The balance of evidence suggests that there has been a northward shift in the tracks of strong low pressure systems (storms) in both the North Atlantic and North Pacific basins.” For North America: "Regional analyses suggest that there has been a decrease in snowstorms in the South and lower Midwest of the United States, and an increase in snowstorms in the upper Midwest and Northeast.”

Despite the progress already made, our understanding of the basic mechanisms by which extremes vary is incomplete. As noted in IPCC (2007), "Incomplete global data sets and remaining model uncertainties still restrict understanding of changes in extremes and attribution of changes to causes, although understanding of changes in the intensity, frequency and risk of extremes has improved." Separating decadal and other shorterterm variability from climate change impacts on extremes requires a better understanding of the processes responsible for the changes. In particular, the physical processes linking sea surface temperature changes to regional climate changes, and a basic understanding of the inherent variability in weather extremes and how that is impacted by atmospheric circulation changes at subseasonal to decadal and longer time scales, are still inadequately understood.

Given the fundamental limitations in the time span and quality of global observations, substantial progress on these issues will rely increasingly on improvements in models, with observations continuing to play a critical role, though less as a detection tool, and more as a tool for addressing physical processes, and to insure the quality of the climate models and the verisimilitude of the simulations (CCSP SAP 1.3, 2008). 
In this chapter we examine the ability of the NASA Goddard Earth Observing System Version 5 (GEOS-5) atmospheric-land general circulation model (AGCM), described in Appendix A, to reproduce cold-season weather extremes, the leading modes of climate variability and associated regional impacts, and the longer-term changes (including changes in extremes) that have occurred during the last three decades. Our focus on the boreal (January - March) and austral (July - September) winter hemispheres, avoids the more challenging warm and transition seasons for which much higher resolution than is typical of climate model simulations is required to adequately represent such extreme weather phenomena as hurricanes, and other mesoscale convective systems that are typical of many continental warm season extremes. Our focus on the last three decades is for the most part dictated by the availability of modern global atmospheric reanalyses (in particular NASA’s high-resolution Modern-Era Reanalysis for Research and Applications - MERRA, Rienecker et al. 2011) and satellite observations, as well as the feasibility of producing an ensemble of multi-decadal AMIP ${ }^{2}$-style simulations at relatively high $(50 \mathrm{~km})$ resolution with the GEOS-5 model.

Section 9.2 examines the simulated and observed leading modes of variability on monthly to interannual time scales as well as the longer-term changes that have occurred over the last three decades, and how these changes impact regional weather and extremes. In section 9.3, we examine more idealized simulations (e.g., doubled $\mathrm{CO}_{2}$; spatially uniform increase in SST) to get a first order sense of how a warmer world might change the nature of climate variability and weather extremes compared to those in our current climate, and what they can tell us (if anything) about the longer-term changes that have occurred in the last three decades. The specific questions that we will address are:

- Does the GEOS-5 model reproduce the observed winter climatological fields?

- Does it have the correct low-frequency (monthly mean) modes of variability?

- Does it have the correct weather variability and extremes?

- Are the linkages between climate variability and regional weather simulated correctly?

- What are the longer terms changes that have occurred over the last three decades and are these reproduced in the model?

- What can idealized AGCM experiments tell us about the recent, and possible future changes in climate variability and weather extremes?

We begin by examining the GEOS-5 model's ability to reproduce the climate means and variations of the last three decades (1980-2009).

\footnotetext{
2 This refers to simulations with atmospheric general circulation models (AGCMs) that are forced with observed sea surface temperatures (SSTs). The name (AMIP) refers to the Atmospheric Model Inter-comparison Project (Gates 1992) in which such runs were, for the first time, done in a coordinated fashion. In the current experiments the model is also forced with the observed GHGs and ozone as described in Appendix A.
} 


\subsection{Observed and Simulated Climate variability and Weather Extremes}

\subsubsection{Boreal winter (JFM)}

Numerous diagnostic studies of extratropical atmospheric variability on monthly and longer time scales (e.g., Quadrelli and Wallace, 2004; Trenberth et al. 2005) have found that the atmospheric circulation is dominated by a relatively few patterns of variability that include the El Nino/Southern Oscillation (ENSO), the Pacific/North American Pattern (PNA), the North Atlantic Oscillation (NAO), the Northern and Southern Annular Modes (NAM and SAM), the Pacific Decadal Oscillation (PDO) and the Atlantic Multidecadal Oscillation (AMO). As discussed below, these patterns of variability have impacts on weather throughout the world. Furthermore, as noted by Kenyon and Hegerl (2008): “.... for reliable attribution of changes in extremes as well as prediction of future changes, changes in modes of variability need to be accounted for.” In particular, that study found considerable influences of ENSO, the NAO, and Pacific interdecadal variability on daily temperature extremes throughout the world.

We focus on January through March (JFM), since these are the winter months during which the Northern Hemisphere (NH) atmospheric response to ENSO SST and the variance of other large-scale middle latitude teleconnections appear to be most robust, including the NAM (e.g., Thompson and Wallace 2000). We also focus on the leading patterns of monthly-mean variability that occurs on interannual time scales and (in the next section) how this variability might change in a warmer world. While we cannot address decadal variability directly ${ }^{3}$, we do examine the impact of the longer time-scale modes of variability indirectly in section 9.2.1.3 as they are reflected in the differences between the first and second half of the last three decades.

ENSO is known to impact weather during JFM in a number of regions throughout the world, primarily over the Pacific Rim and North America, but also parts of Europe and the high latitude Southern Hemisphere (e.g., Fraederich and Muller 1992; Gershunov and Barnett 1998; Kenyon and Hegerl, 2008; Schubert et al. 2008; Chang et. al. 2012; Turner 2004). There is some evidence for an apparent change from eastern Pacific to central Pacific ENSOs (since about 1990 there have been more central Pacific ENSOs, Ashok et al. 2007; Kao et al 2009) and this appears to be consistent with global warming (a flattening of the thermocline - Yeh et al. 2009), although it cannot be excluded that these are natural variations of ENSO (Newman et al. 2011). The potential impacts of such changes in the characteristics of ENSO will be discussed in later sections.

The NAO impacts extremes over much of Eurasia and parts of North America (e.g., Hurrell et al. 2003; Scaife et al. 2008; Kenyon and Hegerl, 2008; Lim and Schubert, 2011). The NAO is, in particular, linked to storm track changes over Europe (e.g., Hurrell 1995; Jones et al. 2003; Hurrell and Deser 2009; Mariotti and Dell’ Aquila 2011).

\footnotetext{
3 While the PDO and AMO are important components of climate variability on decadal and longer time scales and have impacts on extremes (e.g., Chang and Fu 2002), the limited time span (30 years) of our data does not allow us to consider these in any detail.
} 
IPCC (2007) notes that "There is mounting evidence that the recent observed interdecadal NAO variability comes from tropical and extratropical ocean influences (Hurrell et al., 2003, 2004), land surface forcing (Gong et al., 2003; Bojariu and Gimeno, 2003) and from other external factors (Gillett et al., 2003)." The trend in the NAO since 1950 is to more positive values (Hurrell et. al. 2004; Raible et al. 2005) though, as we shall see below, that trend is less evident during the last three decades. Hurrell et al. (2004) indicate that tropical SST forcing (especially in the Indian Ocean) is key to understanding the trend since the 1950s. In fact, they assert that boreal winter North Atlantic climate change since 1950 is well described by the trend in the NAO.

The NAM impacts weather throughout the NH middle and high latitudes (Thompson and Wallace, 2001). It is statistically linked with the NAO (Quadrelli and Wallace, 2004). The NAM has exhibited a trend towards its positive phase between the 1960s and the 1990s, corresponding to a decrease in surface pressure over the Arctic and an increase over the subtropical North Atlantic (Hurrell, 1996; Thompson et al., 2000; Gillett et al., 2003), with somewhat of a decrease after the mid-1990s. The positive phase of the NAM has been associated with a decrease (increase) in winter precipitation over southern (northern) Europe, due a northward shift of the storm track (Thompson et al., 2000).

The trend in the PNA during the period 1950- 2000 is characterized by a general shift toward more negative heights over the Aleutians and the southeastern United States (e.g., as inferred from Raible et. al., 2005). The more recent values of the PNA index ${ }^{4}$, however, suggest that the trend appears to end, if not reverse, in the 1980s (see also next section).

In the following, we assess the ability of the GEOS-5 AGCM to capture the above major modes of climate variability including their spatial structure, time variations, and their links to regional weather. We also assess the extent to which the model reproduces the basic observed weather variability and extremes. The model results are compared with the latest reanalysis data as well as various gridded station observations.

\subsubsection{Climatology and Variability}

In the following, we examine the results of three AMIP-style simulations with the GEOS5 AGCM forced with observed SST, GHGs and ozone covering the period 1980-2009 (see Appendix A for details of the runs). Comparisons are made with MERRA, the NOAA Climate Forecast System Reanalysis (CFSR, Saha et al. 2010), and other gridded observations. The focus in this section is on assessing the quality of the model simulations of the mean climate, the large-scale monthly variability, and the daily weather variability for the 29 boreal winters (JFM) starting in 1981 (since the runs were started in early January of 1980, we discard JFM of 1980 to avoid any spin-up and incomplete months).

Figure 1 (top two rows) shows that GEOS-5 reproduces the observed (MERRA) boreal winter upper tropospheric stationary waves and their monthly variability quite well. Here

${ }^{4}$ http://jisao.washington.edu/data/pna/ 
we include a comparison with another reanalysis (CFSR) to get some sense of the uncertainties inherent in the reanalysis data. That comparison shows that the model stationary waves are, in fact, almost indistinguishable from the reanalysis estimates. The model also reproduces the climatological precipitation pattern and its monthly variability (third and fourth rows of Fig.1), although the simulated variance is somewhat larger than the observed (as estimated from GPCP or MERRA) in the tropics. In addition, the model reproduces the climatological middle latitude storm tracks, although with somewhat weaker amplitude than observed (top panels of Figure 2).

The ability of the model to produce realistic extremes in daily precipitation is evaluated in the second half of Figure 2, which shows the 10-year return values of the daily precipitation maximum. Also shown are the 10-year return values of the warmest days and warmest nights. The return values are estimated by fitting the extremes to the Generalized Extreme Value Distribution (GEV, Coles 2001). Examples of the fits to the GEV distribution are given in Appendix 2. Overall, the simulated extremes look reasonable. The greatest model deficiency appears to be the unrealistically cold day-time temperatures simulated over Canada and northern Eurasia, as it is reflected in the extreme values of the warmest days. There is also a tendency to overestimate the precipitation maxima especially over southern Asia and in the tropics.

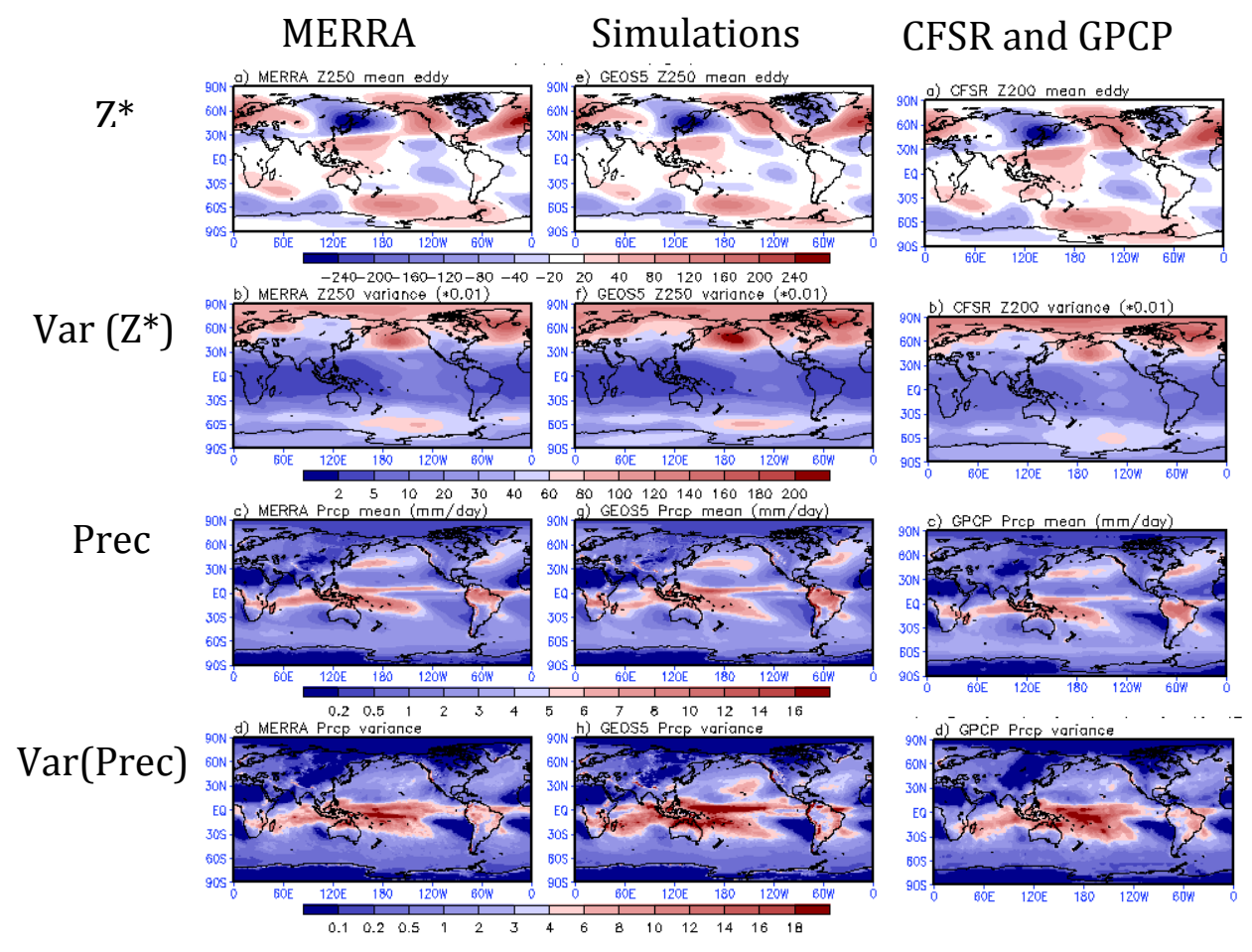

Figure 1: The (JFM, 1981-2009) 250hPa eddy height (Z*) climatology (top row) and monthly variance (second row) fields from MERRA (left panels), GEOS-5 simulations (middle panels), and CFSR (right panels). Units are meters and meters squared times 0.01 , respectively. The third and fourth rows are the same as the first and second rows except for precipitation (Prec) and the right panels are from GPCP observations. Units are $\mathrm{mm} /$ day and $(\mathrm{mm} / \text { day })^{2}$, respectively. 


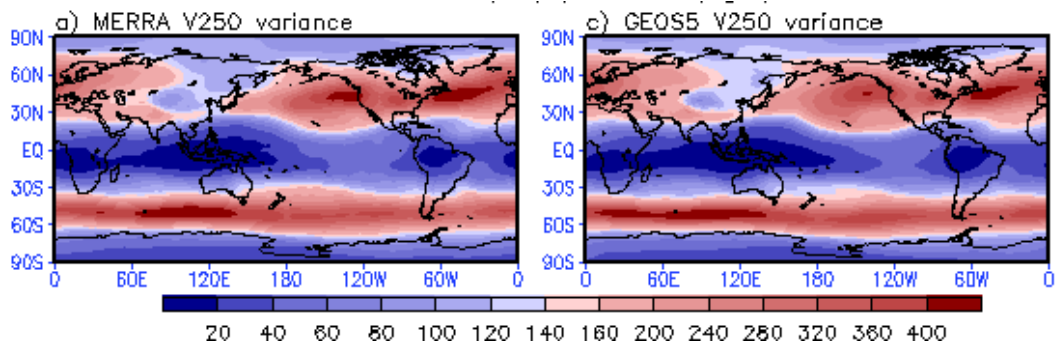

Observations

Simulations

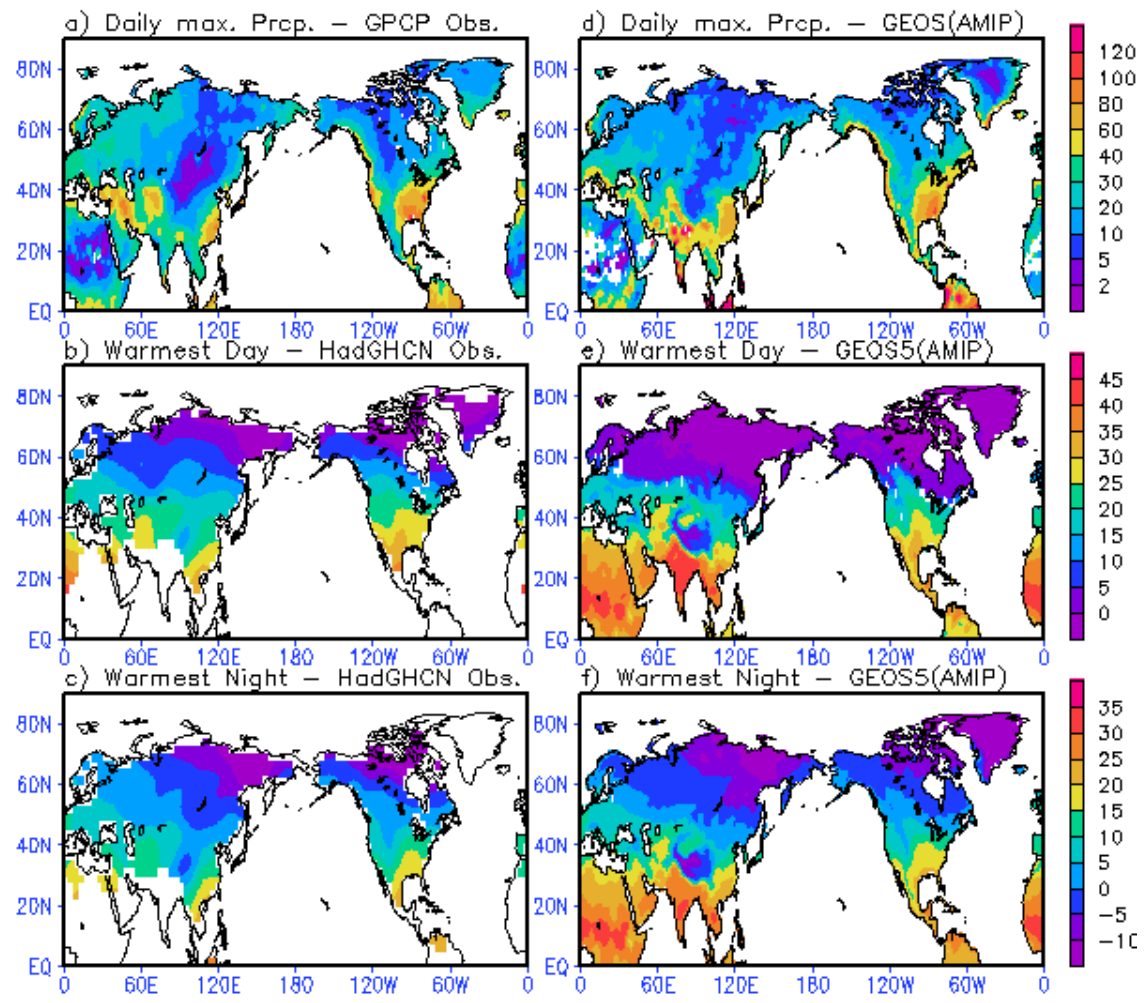

Figure 2: Upper panels: Variance of daily v-wind for JFM (1981-2009) at 250hPa (top) from MERRA (left) and the model simulations (right). The variance is based on daily data. Units are $(\mathrm{m} / \mathrm{s})^{2}$. Lower panels: Maps of 10-year return values for daily maximum precipitation (top, units are $\mathrm{mm} /$ day), warmest day (middle, units are ${ }^{\circ} \mathrm{C}$ ) and warmest night (bottom, units are ${ }^{\circ} \mathrm{C}$ ). Left is for observations (GPCP and HadGHCN), and right is for the AMIP runs. White regions indicate missing or insufficient data to produce reliable fits to the GEVD.

The decomposition of the monthly mean height variability is carried out in terms of a rotated empirical orthogonal function (REOF) analysis (Richman 1986). The resulting four leading REOFs (left most panels of Figure 3) appear to provide a clean separation of the observed (MERRA) variability into patterns consisting of (in order of decreasing 
variance) ENSO, the NAM, the PNA, and the $\mathrm{NAO}^{5}$. The results from the model show a very realistic representation of those patterns although with somewhat different variance. In particular, the main deficiency of the model simulation is a too strong PNA that shows up as the first mode in the simulations (it appears as the third mode in MERRA). The time series of the associated principal components or PCs (panels on the right of Figure 3) show that PC 1 (PC 3 in the model simulations) indeed appears to be linked to ENSO variations as well as a trend towards more positive values, with all three model runs tracking the observed behavior very closely. The PC time series for the model runs and MERRA associated with the second REOF (the NAM), suggest less control from the SST, with the observations showing a tendency toward negative values after the early 1990s. While the model results do not show such a tendency, the observed values do tend to fall
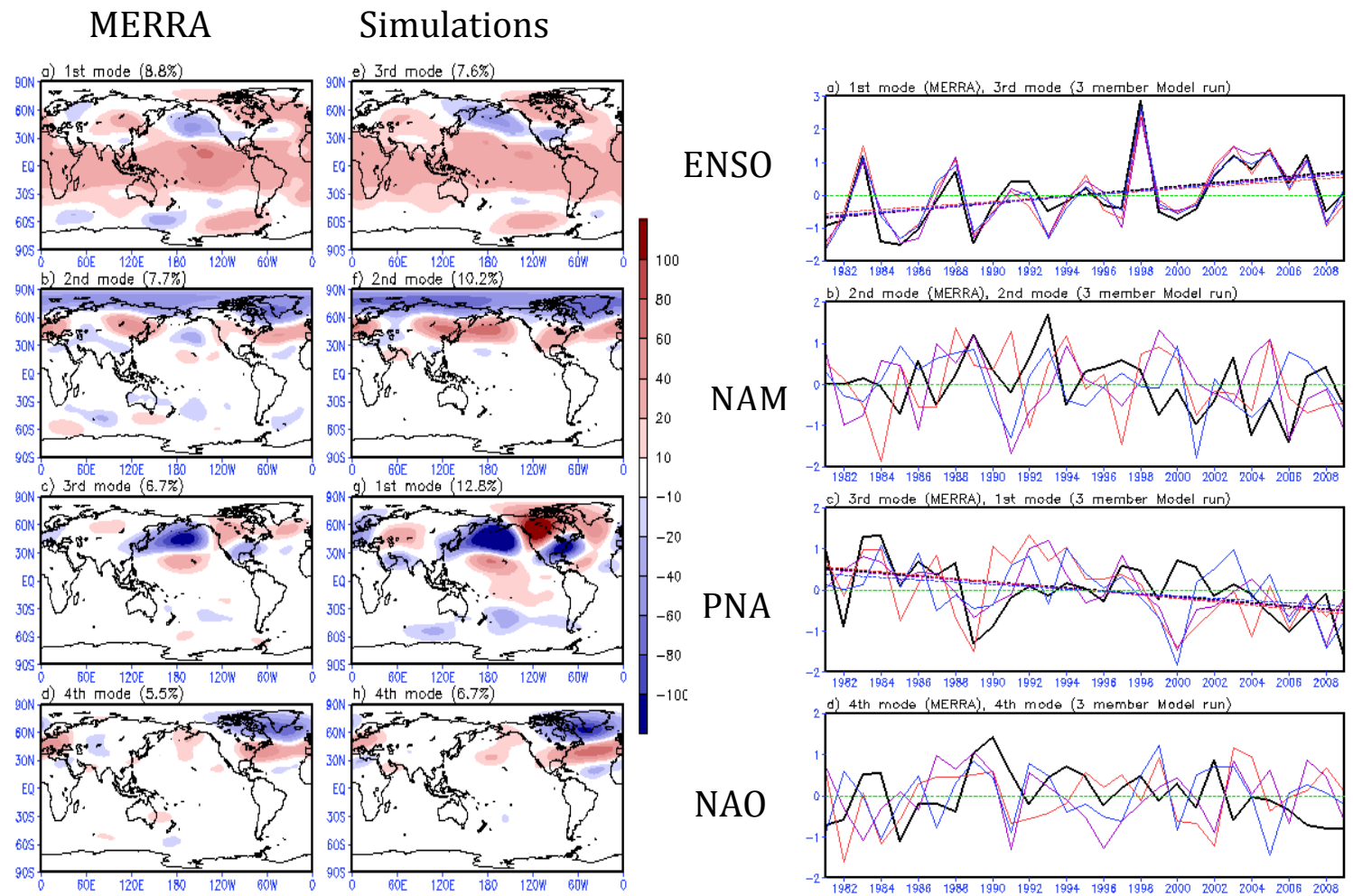

Figure 3: Left set of panels: The four leading rotated empirical orthogonal functions (REOFs) of the monthly 250hPa height field for JFM, 1981-2009. Left panels are from MERRA and the right panels are from GEOS-5 (note the reordering of the GEOS-5 REOFs to match MERRA). Right set of panels: The time series of the four leading PCs. The black line is from MERRA and the colored lines are the three model ensemble members. The monthly values are averaged to produce seasonal (JFM) means before plotting. For the first and third mode the trend lines for each ensemble member and MERRA are significant at the $10 \%$ level. The PCs are normalized to have unit variance, so amplitude information is contained in the spatial maps of the REOFs.

\footnotetext{
${ }^{5}$ We note that the SAM also occurs during the boreal winter, though it does not show here as a leading mode. We shall see later that during austral winter it does show up prominently as the leading mode.
} 
within the spread of the model ensemble. It should be noted that our observed NAM time series is consistent with longer time series ${ }^{6}$ of the NAM (beginning in 1950) that are characterized by predominantly negative values prior to 1985 , with peak positive values occurring in the early 1990s, followed by a negative trend.

The PNA (third REOF for MERRA and $1^{\text {st }}$ in the model runs) shows a trend toward more negative values. As discussed earlier, longer time series starting in 1950 show that this downward tendency follows an extended period of an upward tendency that peaked in the mid 1980s. Here, the observed and simulated behavior does show some similarity suggesting some dependence on SST or GHGs, although that appears to be stronger for the model runs (the individual ensemble members are more similar to each other than to MERRA). The time variability of the NAO (fourth REOF) shows little control from any external forcing, although the three model simulations again seem to be more similar to each other than to MERRA. There is no obvious trend, but there is again (like for the NAM) some tendency toward more negative values for the observations in recent years. This is part of a longer-term variability ${ }^{7}$ that resembles the behavior of the NAM, characterized by primarily negative values from 1950-1980, with peak maximum values in the early 1990s, followed by the downward trend.

The above results indicate that the various modes of variability consist of some patterns that are externally forced (by SST or GHGs or ozone) and others that are internal to the atmosphere, with some evidence that the latter may be impacted (modulated) by external forcing. We shall see in Section 9.3, that the NAM, PNA and NAO are indeed fundamentally internal (to the atmosphere) modes of variability, in that they appear as the leading REOFs of model simulations that have no interannual variability in external forcing (SST, GHGs, or ozone).

\subsubsection{Regional Impacts of Climate Variability}

We next turn to an evaluation of the relationships between the variations of the boreal winter leading large-scale modes of variability (ENSO, NAM, PNA, NAO) and regional weather including changes in storminess, near surface temperature, and precipitation. Results are presented for both MERRA (or gridded observations) and the model simulations. In the latter case, the correlations are the average of the correlations computed for each ensemble member. In all cases, a linear trend is removed before computing the correlations.

Overall, the results show that the main features of the regional impacts of the climate modes are well reproduced by the model (Figure 4). This includes the enhanced storminess and precipitation along the US Gulf States during El Nino, the warmer (colder) temperatures over northern Eurasia (the Mediterranean and North African regions) during a positive NAM, the increased storminess and warming over northern Europe and the warming over the US eastern seaboard during a positive NAO, and the

\footnotetext{
6 http://www.cpc.ncep.noaa.gov/products/precip/CWlink/daily_ao_index/JFM_season_ao_index.shtml

7 http://www.cpc.ncep.noaa.gov/products/precip/CWlink/pna/JFM_season_nao_index.shtml
} 
warming over Alaska and western Canada during a positive PNA. The main deficiency appears to be that the PNA is more strongly tied to SST variability than is observed.

Specific features of the ENSO-related correlations (panels on the top left side of Figure 4) include a substantial El Nino warming throughout the tropics in all ocean basins, with the typical off-equatorial cooling in the Pacific. The correlations over the extratropical land areas are generally weak, with the model showing more pronounced correlations over North America than MERRA. The precipitation correlations show the typical ENSO-related pattern in the Pacific, with positive values over the central and eastern tropical Pacific and negative values in the Pacific warm pool that extend eastward into the subtropics of both hemispheres. The sea level pressure (SLP) correlations are consistent with the Southern Oscillation pattern. The weather variance, as estimated by the daily meridional wind variability $\left(\mathrm{v}^{, 2}\right)$, shows negative correlations in the central Pacific and positive correlations in the tropical Atlantic and the Indian Ocean and parts of the Pacific warm pool. The enhanced (reduced) storm track along the U.S. southern tier of states during El Nino (La Nina) is clearly evident in both the simulations and MERRA.

The correlations of both the MERRA and simulated temperatures two meters above the ground (T2m) with the NAM (top right panels of Fig. 4) are characterized by negative values over the Arctic and Greenland, positive values over northern Scandinavia and Russia extending eastward to Japan, and again negative values over Northern Africa and parts of southern Asia. The precipitation correlations are positive over much of northern Russia (with a tendency for negative values to south) and Scandinavia. The SLP exhibits negative correlations in the Arctic (north of $60^{\circ} \mathrm{N}$ ) and primarily positive values south of that, with the model showing positive correlations in the eastern Pacific that are not in the MERRA results. The correlations with $\mathrm{v}^{2}$ show positive values across northern Russia and Scandinavia, and a tendency for negative values to the south in the latitude band $30^{\circ} \mathrm{N}-40^{\circ} \mathrm{N}$, though the observed negative correlations over the US are not reproduced in the model results.

The observed and simulated PNA correlations (bottom left panels of Figure 4) exhibit negative values for T2m over the western North Pacific and southeastern US, with positive values over much of northwest North America. The simulations show a substantial region of positive correlations with $\mathrm{T} 2 \mathrm{~m}$ over the central and eastern tropical Pacific that indicate a too strong link to SST variability. The precipitation correlations are positive over the North Pacific extending into the Gulf of Alaska, and these are flanked by negative correlations to the north and south. Positive correlations also occur in the tropical Pacific and in the Gulf of Mexico extending into the North Atlantic. The correlations with SLP are consistent with the height anomalies, and are dominated by negative correlations in the North Pacific and the southeast U.S., and a tendency for positive correlations in the eastern tropical Pacific and (for the model) also in the Indian Ocean. Correlations with v'2 are mostly negative over the North Pacific, and the U.S., with some positive correlations (more so for the model) extending from the eastern subtropical Pacific across Mexico and into the Atlantic. 
The observed and simulated NAO correlations (bottom right panels of Figure 4) exhibit positive values for T2m over much of Europe and Russia, and the southeast United States. Negative correlations occur over northeastern North America and Greenland, as well as northern Africa. Correlations with precipitation show a north/south dipole over the North Atlantic and Europe (positive over Northern Europe) and that is reflected to some extent by a north/south dipole in the correlations with weather variability (positive over Northern Europe). Correlations with SLP are primarily negative north of $60^{\circ} \mathrm{N}$ and positive over the North Atlantic (south of $60^{\circ} \mathrm{N}$ ) and northern Africa.

\subsubsection{Long-Term (Decadal Scale) Changes}

In the previous sections we examined the variability on monthly time scales, and found that the leading modes of variability and their connections with weather and regional surface meteorology are generally well simulated by the model. Time series of these modes showed that they vary on both interannual and longer time scales, with a few modes showing clear evidence of trends over the three decades examined here. In this subsection we look more directly at the longer-term changes that have occurred, as they are reflected in the differences between the first and second half of the record.

Figure 5 shows the observed (MERRA and GPCP) and model simulated differences in the $250 \mathrm{hPa}$ height, daily weather variability $\left(\mathrm{v}^{2}\right), \mathrm{T} 2 \mathrm{~m}$, and precipitation. The most pronounced differences in the $250 \mathrm{hPa}$ height field between the two periods in both MERRA and the simulations is the overall increase in the tropics and subtropics and a decrease in the tropical eastern Pacific. The observations show a height decrease in the southern polar region, and an increase in height in the northern polar region: these are absent from the model simulations. The latter reflects the general trend towards more negative values of the NAO after 1990 in the observations (see e.g., Fig. 3). The weather variability (second row of Fig. 5), shows a distinct poleward shift in the SH in both the observations and simulations. Over North America, there is an increase in weather variability over Canada and a decrease over the US southern tier of states. There is little agreement between the observations and model results over Eurasia in terms of the changes in weather variability. The surface temperature changes show a general warming, with cooling over western Canada, Alaska, and (for the observations) over northern Russia. Over the ocean the temperatures have warmed over the North Atlantic, much of the western Pacific and parts of the Indian Ocean. In contrast, the eastern Pacific shows some evidence of cooling. This appears to be part of a longer-term trend extending back at least one half century (e.g., Kumar et al. 2010). The precipitation differences in the Pacific resemble the response to La Nina, with reduced precipitation in the tropical central and eastern Pacific extending poleward in both hemispheres (across the southern US and towards the southern tip of South America). The Pacific warm pool and the tropical Atlantic both show enhanced precipitation. The above changes in precipitation are consistent with those described in Hoerling et al. (2010).

Kumar et al. (2010) note that for the recent period (1980-2008), the global teleconnection pattern associated with La Niña has been associated with higher heights than in previous decades from the tropics to the mid-latitudes. In Figure 6 (top panels) we remove the 
ENSO
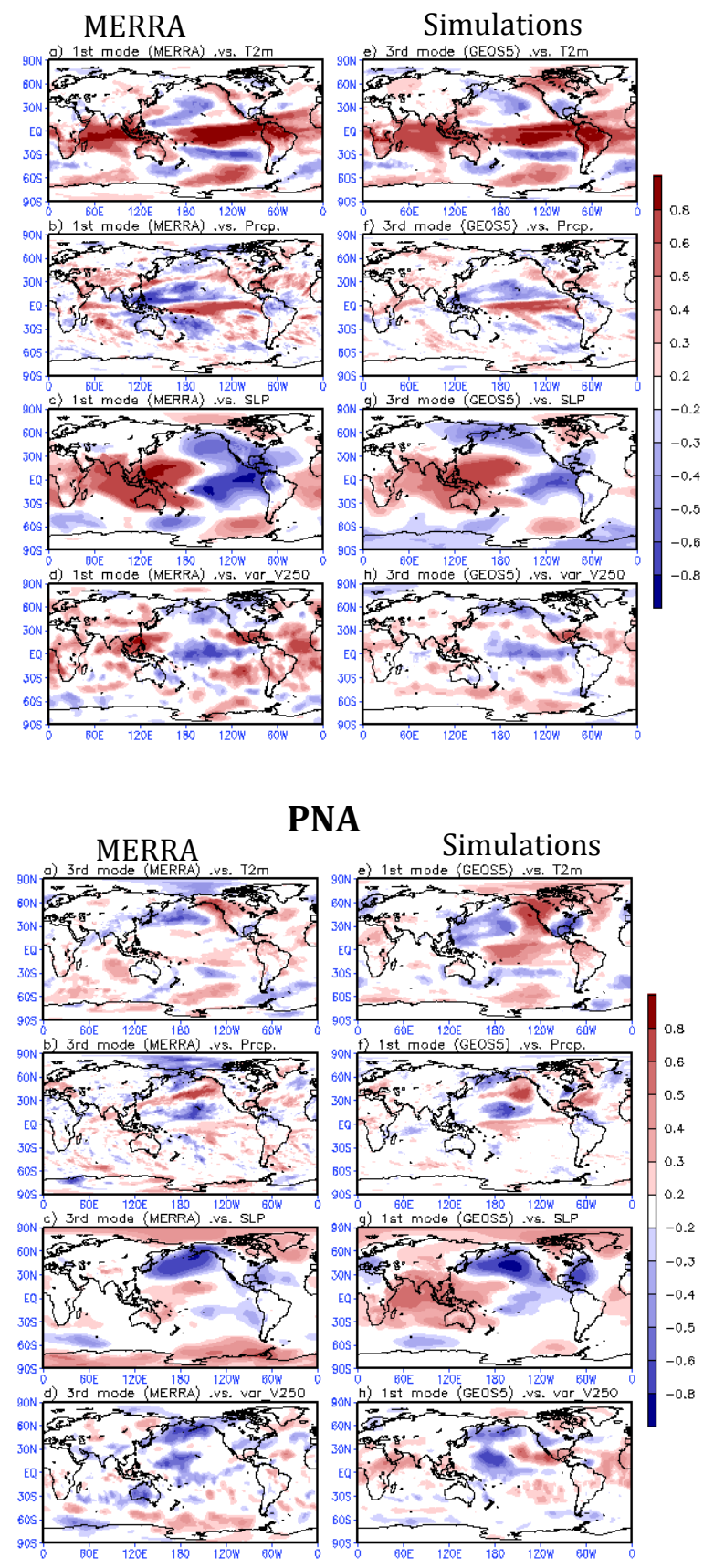

PNA

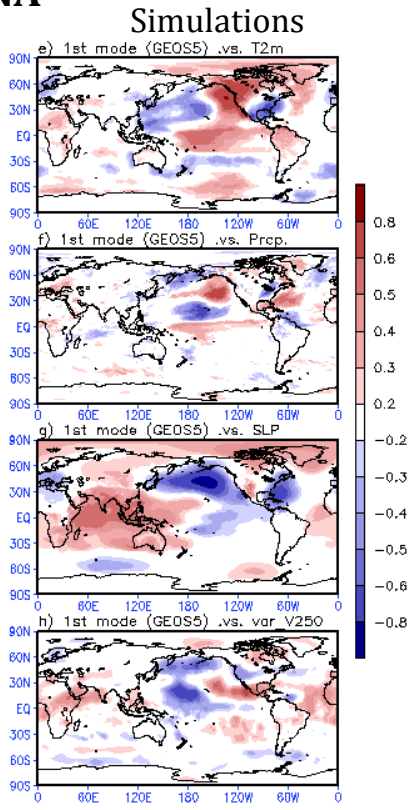

NAM

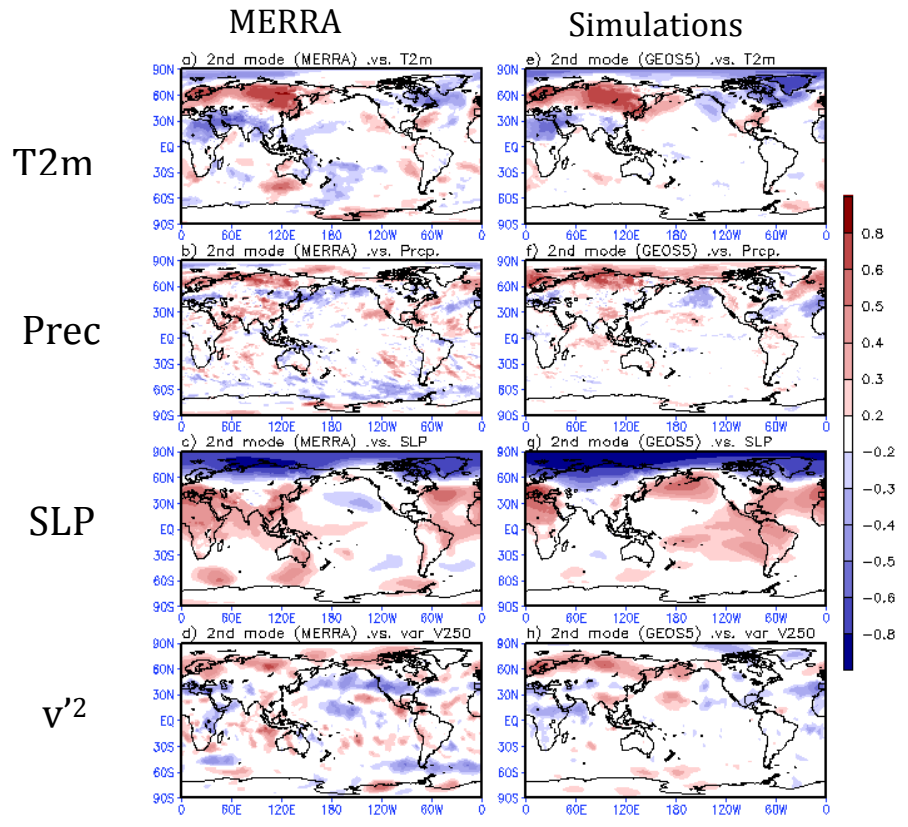

NAO

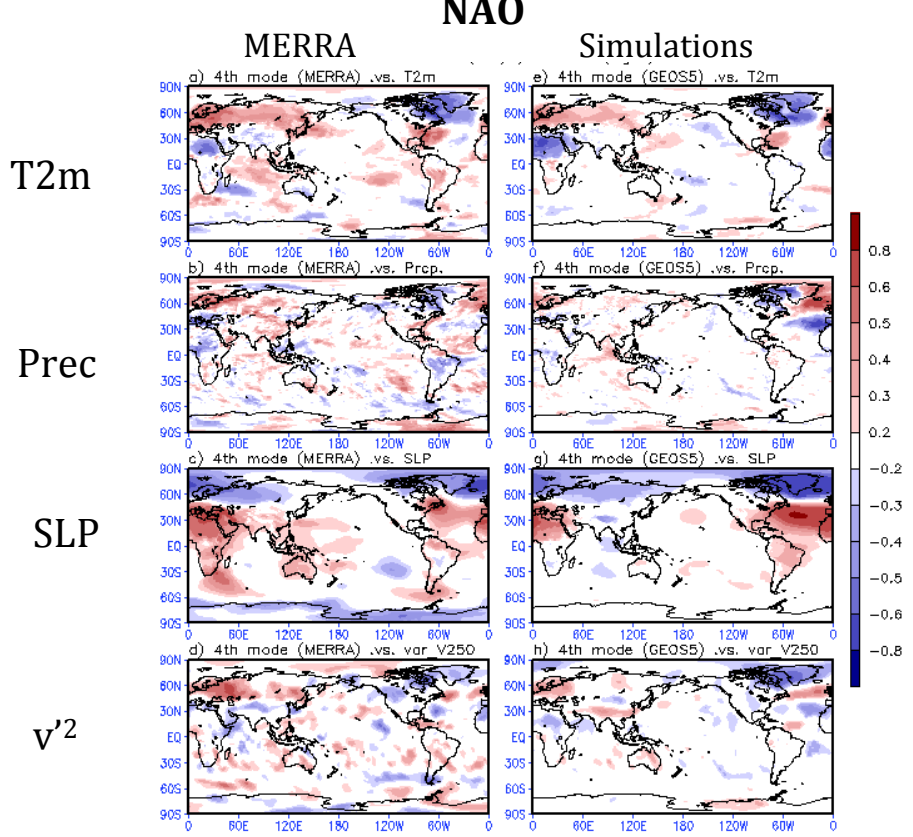

Figure 4: Correlations between the leading monthly REOFs (the corresponding PCsseasonally averaged) and seasonal mean $T 2 \mathrm{~m}$, precipitation, sea level pressure, and $250 h P a v^{2}$. For each set of panels, the results for MERRA are on the left and the results for GEOS-5 are on the right. Top left set of panels: MERRA REOF 1 and GEOS-5 REOF 3. Top right set of panels: MERRA REOF 2 and GEOS-5 REOF 2. Bottom left set of panels: MERRA REOF 3 and GEOS-5 REOF 1. Bottom right set of panels: MERRA REOF 4 and GEOS-5 REOF 4. Values are detrended before computing the correlations. The model results are the average of the correlations computed separately for each ensemble member. 
Observed

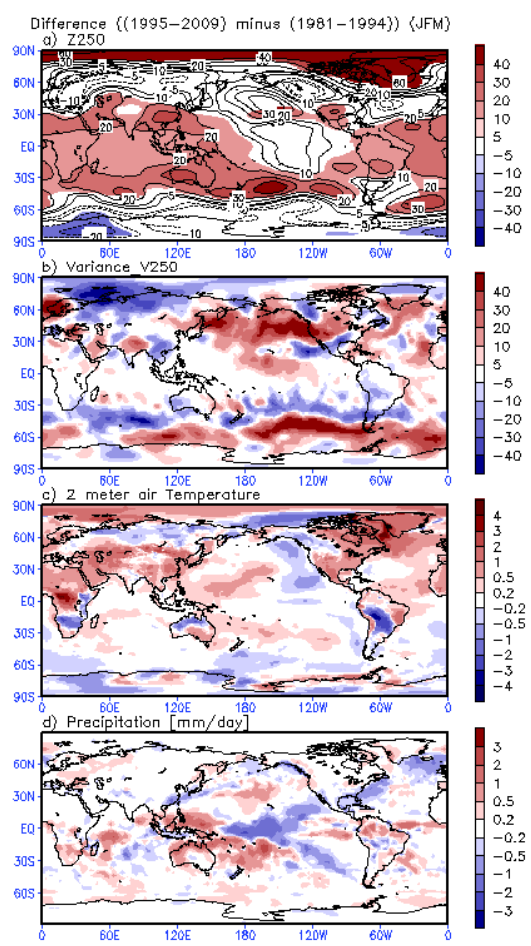

Simulated

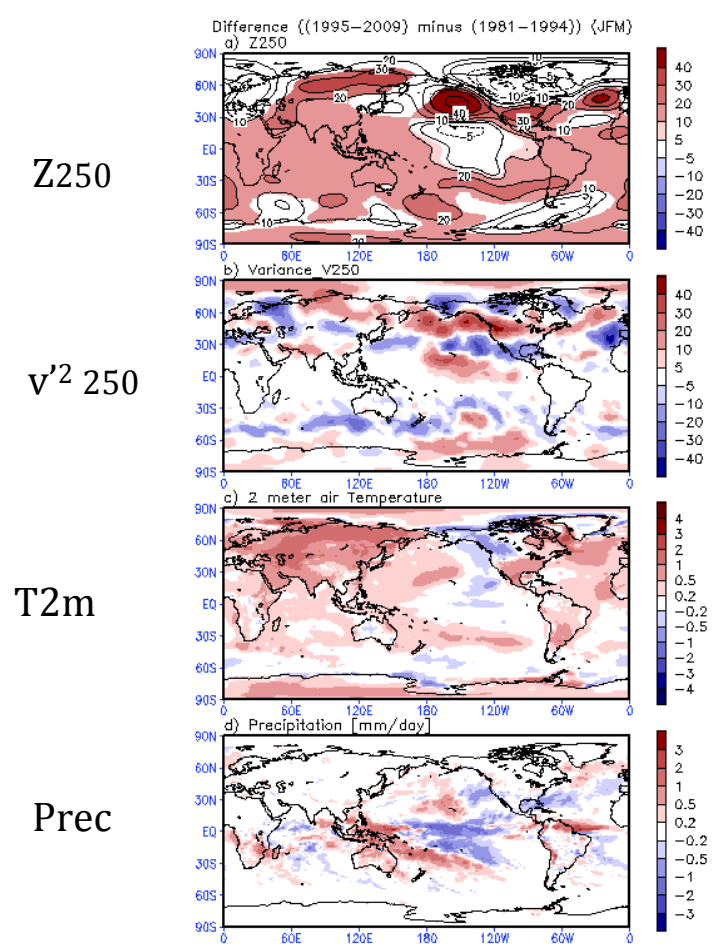

Fig. 5: The difference between the means: (1995-2009) minus (1981-1994) for JFM. The left panels are for the observations (MERRA and GPCP precipitation) and the right panels are for the AMIP runs. Top panels are the 250hPa height differences (only values significant at the $10 \%$ level are shaded, units are meters), the second row consists of the differences in the $250 \mathrm{mb}$ daily $\mathrm{V}$-wind variance (units are $\mathrm{m} / \mathrm{s}$ squared), the third row shows the 2 meter temperature differences (units are ${ }^{\circ} \mathrm{C}$ ), and the last row shows the precipitation differences (units are $\mathrm{mm} /$ day).

MERRA
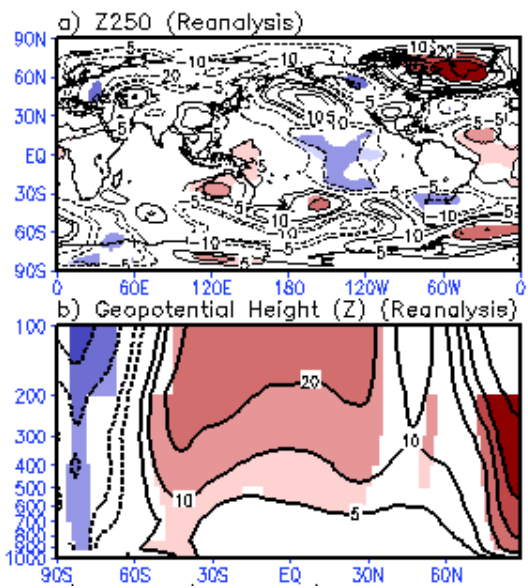

Simulated

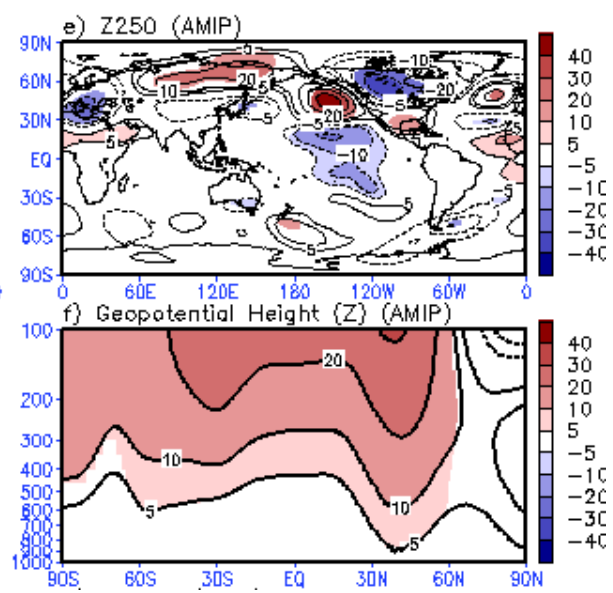

Fig. 6: The difference between the means: (1995-2009) minus (1981-1994) for JFM. The left panels are for MERRA and the right panels are for the AMIP runs. Top panels are the 250mb height differences with the zonal mean removed. The second row displays the zonal mean height difference (only values significant at the $10 \%$ level are shaded). Units are meters. 
Diff, in return volues for the number of roin day ( $>5 \mathrm{~mm} / \mathrm{day}$ ), warm days ( $>90 \%$ Tmax.), and cold nights $(<10 \%$ Tmin.) in JFM (return period: 10 year)

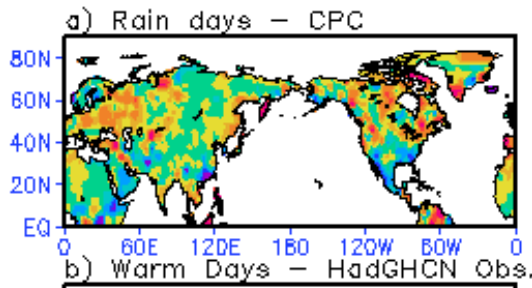

d) Rain doys - MERRA

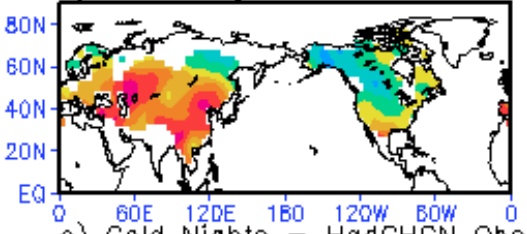

c) cold Nights - HadGHCN obs.
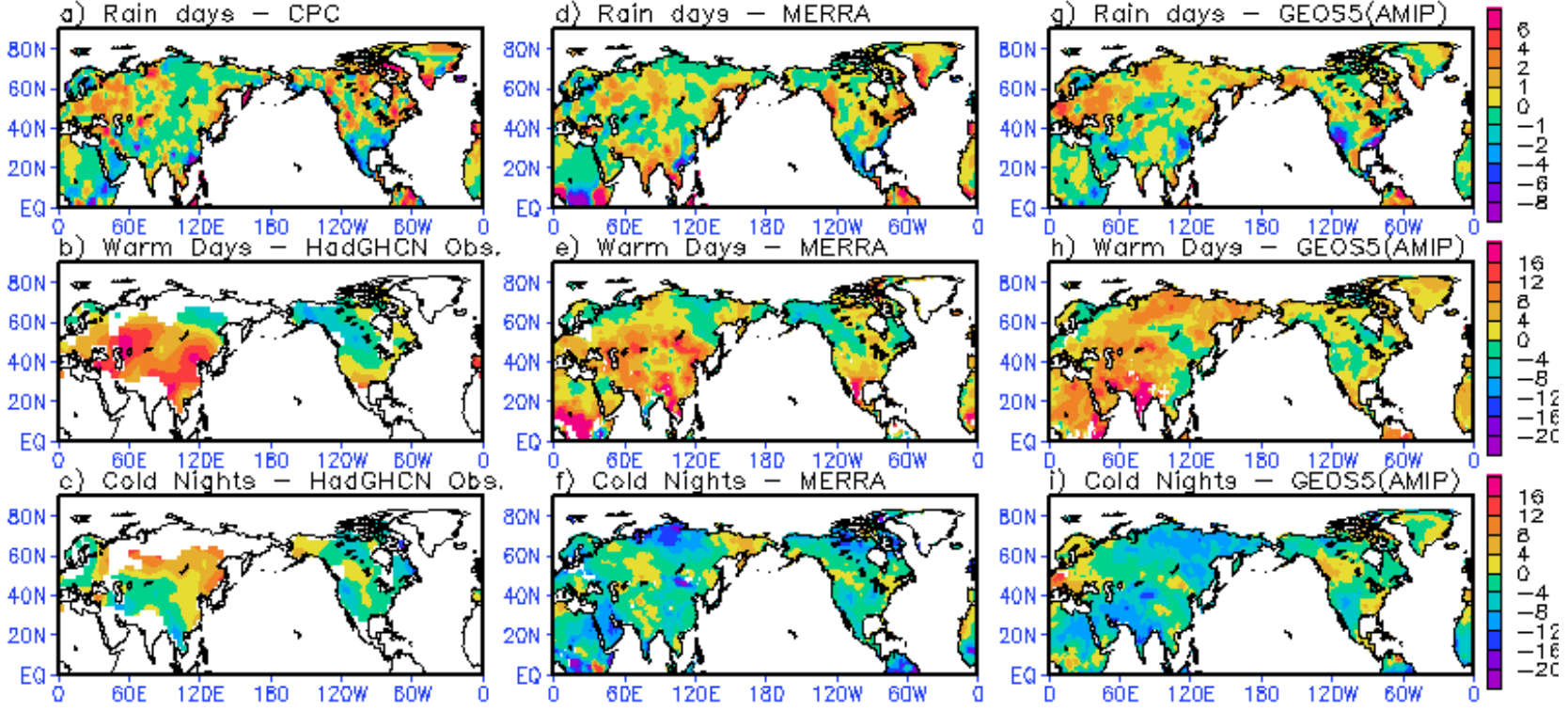

Fig. 7: The difference (JFM, 1995-2009 minus 1981-1994) in the 10-year return values of the number of heavy rain days ( $>5 \mathrm{~mm} /$ day), warm days (greater than the $90^{\text {th }}$ percentile of the daily maximum temperatures) and cold nights (less than the $10^{\text {th }}$ percentile of the daily minimum temperatures) for observations (left panels), MERRA (middle panels) and AMIP runs (right panels). Results are based on fits of the exceedances to a GPD.

"background" height increase by removing the zonal mean heights before computing the 250hPac height differences. This shows more clearly the canonical La Nina response in the eastern Pacific with anomalies extending northward and eastward across North America. The cross section of the zonal mean height differences highlights the general height increases that maximize above 200hPa. The zonal means also emphasize the differences between the model and MERRA at high latitudes noted earlier.

The changes in the extremes between the two time periods are depicted in Fig. 7 in terms of the differences in the 10-year return values of the number of heavy rain days, warm days, and cold nights. Results are based on a fit of the exceedances to a Generalized Pareto Distribution (GPD, Coles 2001). This approach has the advantage over the block maxima approach applied earlier to the maxima (e.g., Fig. 2), in that it uses more data this is especially important here in view of the short (15 year) records for the two time periods. The results for the changes in the number of heavy rain days show general agreement between the observations, MERRA, and simulations, although there are differences in the details. The reduction in the number of heavy rain days in the southern United States is prominent in all three. So is the increase over eastern Russia, Canada, southern Asia, and northeast Brazil. The main discrepancy with the simulations occurs over northern Russia, where the model shows an increase and the observations and MERRA show a slight decrease in the number of heavy rain days. 
The spatial pattern of the differences for the number of warm days to a large extent reflect the distribution of the differences in the mean temperature (Fig. 5c), with an increase in the number of warm days over much of central and southern Asia, and the southern United States and Mexico. The apparent reduction in the number of warm days over northern Asia for the observations (and MERRA) versus an increase for the model is not inconsistent with the difference between the observed/MERRA and simulated mean temperature changes in that region (Fig. 5c). Over northwest North America, the observations and MERRA also show a reduction in the number of warm days while the model results are mixed.

The largest discrepancies with the observations occur for the changes in the number of cold nights, with the model and MERRA showing a general decrease over much of Asia, while the observations indicate an increase especially over central and northern Asia, though the northern areas have a substantial number of missing observations during the last decade. Over North America, there is more agreement with all three showing a tendency for an increase in the number of cold nights over the Pacific Northwest, and a decrease over the southwest.

Overall, the simulated (and MERRA) temperature extremes appear to reflect the basic shift to warmer conditions, with a general increase in the number of warm days and a decrease in the number of cold nights. This is less so for the observations, though that may be largely an artifact of gaps in the temperature record. 


\subsubsection{Austral Winter (JAS)}

We turn next to the austral winter. In this case, we choose the Southern Hemisphere (SH) late winter three-month period of July, August and September (JAS), as the appropriate juxtaposition with the late boreal winter period, JFM. The SH winter is also (like the boreal winter hemisphere) characterized by a number of distinct modes of variability on monthly and longer time scales. Perhaps the best know is the Southern Annular mode (SAM; Thompson and Wallace, 2000) already mentioned earlier. As reported in IPCC (2007), the SAM has exhibited an upward trend over the past 30 years, corresponding to a decrease in surface pressure over the Antarctic and an increase over the southern mid-latitudes although the mean SAM index since 2000 has been below the mean of the late 1990s, but above the long term mean. An upward trend in the SAM has occurred in all seasons, but the largest trend occurs during the southern summer (Mo 2000; Thompson et al., 2000; Marshall, 2003). Based on an analysis of the structure and seasonality of the observed trends in SH circulation, Thompson and Solomon (2002) suggest that the trends have been largely induced by stratospheric ozone depletion. In contrast, Ding et al. (2011) report that, while the SAM exhibits an upward trend during the summer, during winter it has exhibited a negative trend since 1979, associated with an increase in geopotential heights over high latitudes. This appears to be in part due to the nature of the SAM index, which is a superposition of both intrinsic high latitude variability and a tropically-forced component. The SAM is known to have impacts on South America (Silvestri, G. E., and C. S. Vera, 2003), Australia (Hendon et al. 2007), New Zealand (Kidston et al. 2009), South Africa (Reason and Rouault 2005), and the Antarctic Peninsula (Lefebvre et al. 2004).

In addition to the SAM, there are several distinct wave structures that are the counterparts to the PNA in the NH, consisting of the Pacific South American (PSA) modes 1 and 2 (Kidson 1988; Ghil and Mo 1991; Mo 2000). These zonal wave 3 structures extend from the tropical South Pacific poleward and eastward across southern South America. Both PSAs have been linked to variations in ENSO (e.g., Karoly 1989; Mo 2000)

Before examining the modes of variability, we again begin by first looking at the ability of the model to simulate the basic climatological fields and overall variability.

\subsubsection{Climatology and Variability}

The model captures that JAS stationary wave pattern quite well (Figure 8, top panels). Again, as during JFM, the correspondence in the details of the JAS troughs and ridges in both hemispheres is almost indistinguishable from the two reanalysis estimates. The variance patterns are also well simulated included the region of enhanced variability in the SH high latitudes near 120W. The basic precipitation pattern is simulated well, although the area of Pacific warm pool precipitation extends too far north in the western Pacific, and the precipitation in the eastern end of the Pacific ITCZ is excessive. The overall pattern of precipitation variance is quite realistic and reflects the spatial distribution of the mean precipitation, although the amplitude is excessive. 
As an overall assessment of weather activity we again focus on the patterns of daily $\mathrm{v}^{, 2}$ at 250hPa. This shows (Figure 9, upper panels) that the model reproduces the basic patterns of SH weather variability quite well, matching both the spatial pattern and amplitude of the variability. We note that in the $\mathrm{NH}$, the simulated weather variability is overall weaker than observed during this season, especially in both storm tracks although the regions of the maxima in variance are again quite realistic.

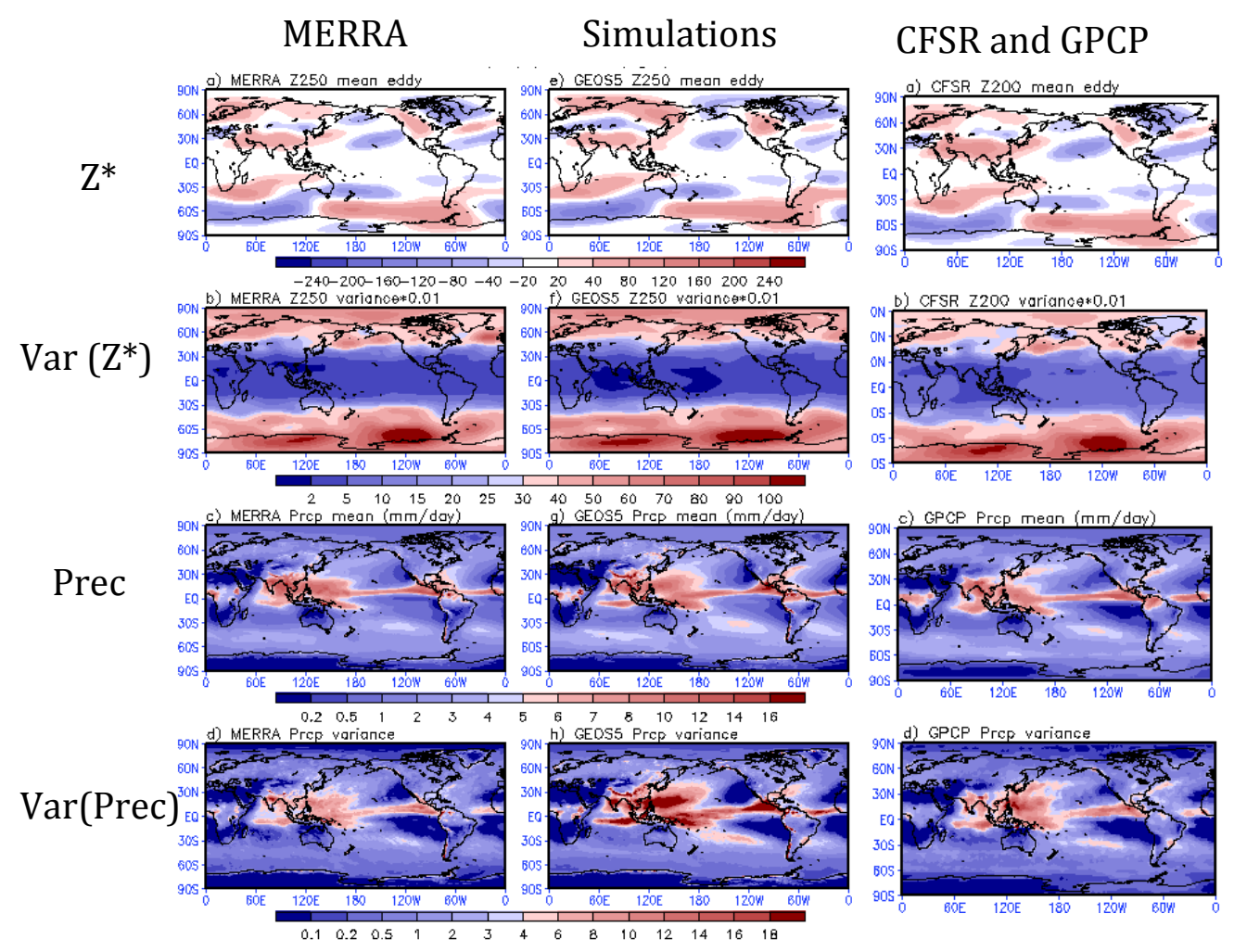

Figure 8: The (JAS, 1980-2009) 250hPa eddy height climatology (top row) and monthly variance (second row) fields from MERRA (left panels), GEOS-5 simulations (middle panels), and CFSR (right panels). Units are meters and meters squared times 0.01, respectively. The third and fourth rows are the same as the first and second rows except for precipitation and the right panels are from GPCP observations. Units are $\mathrm{mm} /$ day and $(\mathrm{mm} / \text { day })^{2}$, respectively.

The 10-year return values of the precipitation maxima (Figure 9, lower panels) are simulated reasonably well over Australia, Africa and South America during JAS, although the amplitude tends to be too large. Also shown in Figure 9 are the 10-year return values of the warmest day and warmest night. The comparison is to a large extent limited to Australia (due to insufficient daily temperature observations over most of the rest of the SH land areas). While the spatial pattern of the temperature extremes over Australia look reasonable, the values are too large indicating a warm bias in the model. 


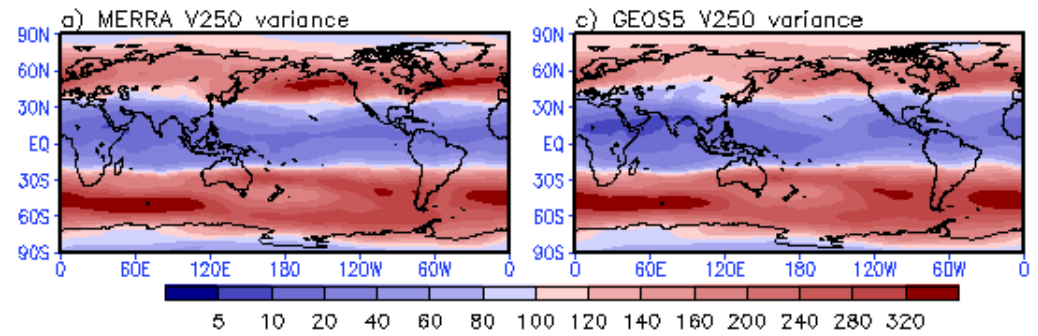

Observations

Simulations

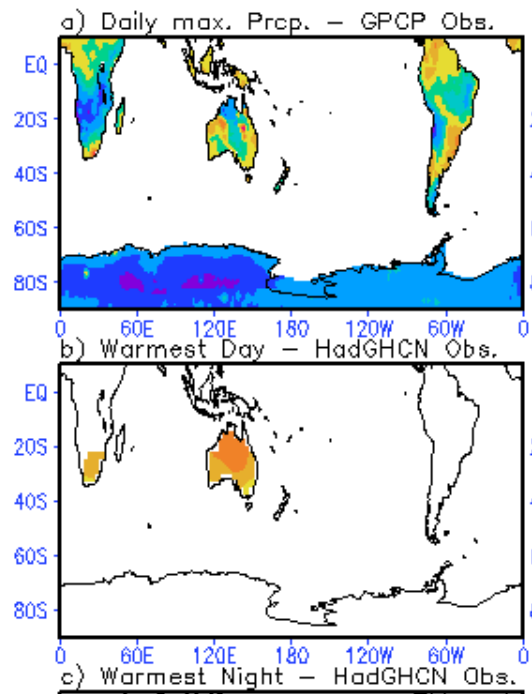

d) Daily max. Prep. - GEOS(AMIP)

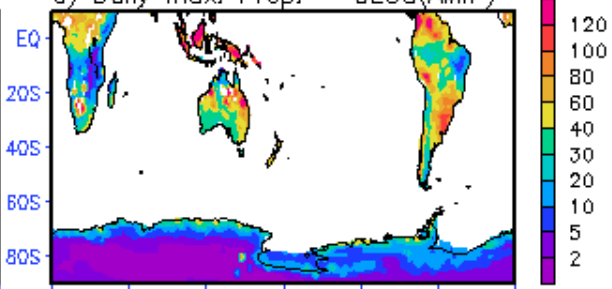

e) Warmest Doy - GEOS5(AMIP)
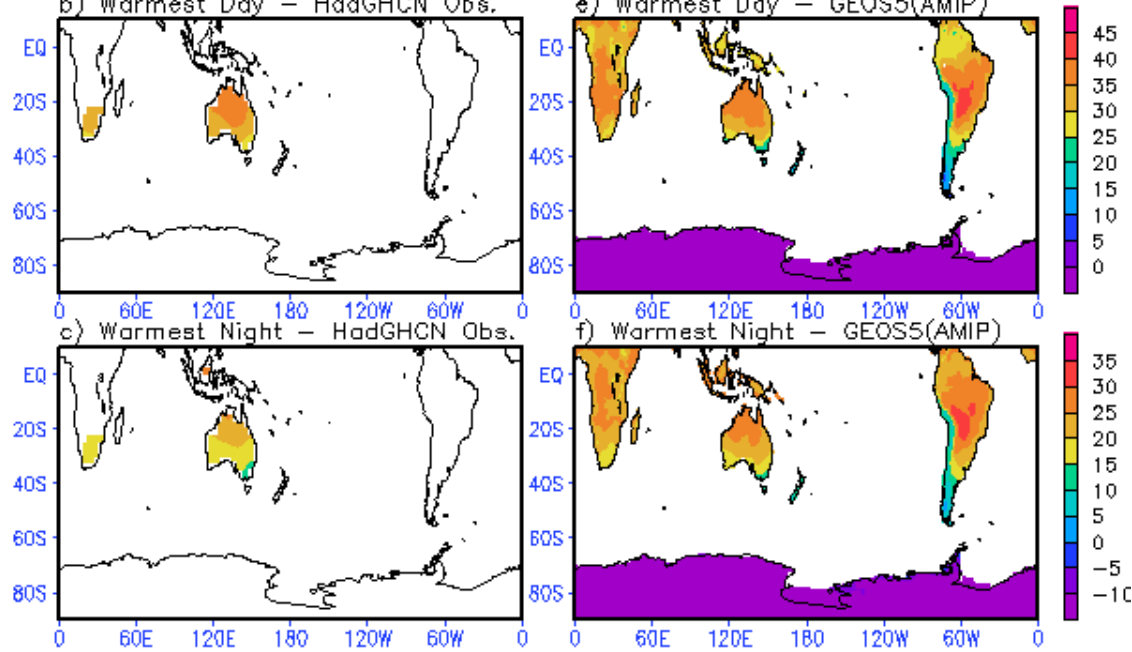

Figure 9: Upper panels: The 250hPa (top) variance of the v-wind for JAS, 1980 -2009. The variance is based on daily data. Left panels are from MERRA and the right panels are from the model runs. Lower panels: Maps of 10-year return values for daily maximum precipitation (top, units are mm/day), warmest day (middle, units are ${ }^{\circ} \mathrm{C}$ ) and warmest night (bottom, units are ${ }^{\circ} \mathrm{C}$ ). Left is for observations (GPCP or HadGHCN), and right is for the AMIP runs. White regions indicate missing or insufficient data to produce reliable fits to the GEVD.

We next turn to the REOFs of the 250hPa height field. The four leading REOFs are shown in the left panels of Figure 10. The first is clearly associated with the SAM, showing a zonally symmetric structure, with however, maximum loadings in the eastern hemisphere (Indian Ocean sector), in both the observed and simulated patterns. The PCs associated with the SAM (upper right panel) show little coherence and no apparent trends. While previous studies have found an upward trend in the SAM over the last thirty years, 
observations show that this is largely confined to the SH summer and autumn months (Marshall 2003).

The second REOF (third in the model simulations) has a zonal wave number 3 structure extending across the middle latitudes of the Southern Hemisphere (with the largest amplitude in the South Pacific and South Atlantic). The variations do not seem to be strongly forced (little coherence among the ensemble members) but there is some suggestion that the waves emanate from the Pacific warm pool. The third REOF (the second REOF in the model simulations) is associated with an almost uniform global height increase and a very robust upward trend. The fourth REOF has a wave structure confined to the South Pacific Ocean (south of $30^{\circ} \mathrm{S}$ ), and also seems to have little if any coherence among the ensemble members or with MERRA. We shall see in Section 9.3 that for JAS, REOFs 1, 2 and 4 (as defined by MERRA) are the leading internal atmospheric modes of variability, analogous to the NAM, PNA, and NAO during JFM.
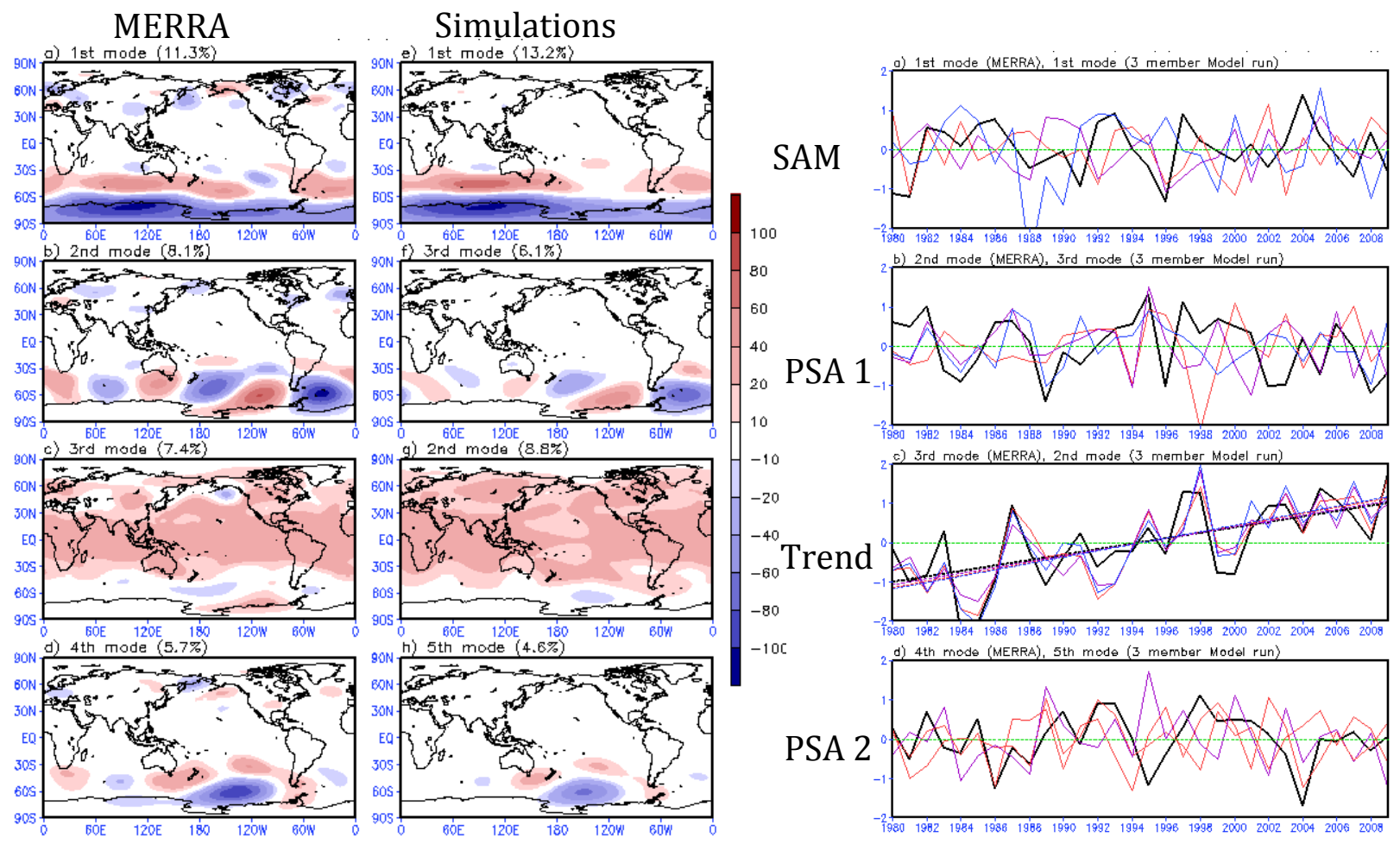

Figure 10: Left set of panels: The four leading rotated empirical orthogonal functions (REOFs) of the monthly 250hPa height field for JAS, 1980-2009 (note for the model the second and third REOFs are switched). Left panels are from MERRA and the right panels are from GEOS-5. Right set of panels: The time series of the four leading PCs of the height field REOFs. The black line is from MERRA and the colored lines are the three model ensemble members. The monthly values are averaged to produce seasonal (JAS) means before plotting. For the third mode the trend lines for each ensemble member and MERRA are significant at the $10 \%$ level. The PCs are normalized to have unit variance, so amplitude information is contained in the spatial maps of the REOFs. 


\subsubsection{Regional Impacts of Climate Variability}

We next focus on the regional impacts of the four 250hPa REOFs (Figure 11). The top left panels of Fig. 11 show the T2m correlations with the SAM (the leading 250hPa REOF). Correlations are strongest (negative values) over Antarctica in the eastern hemisphere, with weak positive values over parts of the Southern Oceans. The results for MERRA show positive correlations over the eastern tropical Pacific with negative correlations in the western Pacific, suggestive of an ENSO connection (see also Qinghua et al. 2011). In contrast, the simulations show only very weak correlations in the tropical Pacific, indicating a much weaker link to ENSO. Both model and MERRA show weak but coherence correlations with precipitation with alternating bands of negative correlations over Antarctic, positive correlations just north of Antarctica and again negative correlations just south of Australia. The correlations with SLP show a very clear pattern of negative correlations over Antarctic and positive correlations over the Southern Indian Ocean. The observed and simulated correlations with v'2 also show alternating bands of negative and positive correlations (negative over Antarctica, positive just north of that, and again negative correlations in the southern Indian Ocean) extending eastward along the southern coast of Australia, New Zealand, and further east into the south Pacific.

The correlations with the third MERRA (second model) REOF (the Trend mode) are shown in the bottom left set of panels of Figure 11. The correlations with T2m show that the strongest positive correlations occur over the northern Indian Ocean, parts of the Pacific warm pool, the far eastern tropical Pacific, and the Atlantic warm pool extending eastward across the Atlantic. Over the land areas the correlations tend to be positive, including parts of North America, northern South America, southern Asia, and northern Africa. Correlations with precipitation tend to be weak and disorganized, with the most coherent correlations occurring in the Pacific ITCZ (where they are positive) and across northern South America where the correlations are negative. Correlations with SLP are weak and show little agreement between the model and MERRA. MERRA has positive correlations over Indonesia, while the model has positive correlations over the central tropical/subtropical Pacific. Correlations with $\mathrm{v}^{2}$ are weak and disorganized but tend to be positive, especially for MERRA.

Finally, we also show in Figure 11 the correlations with the second and fourth REOFs corresponding to PSA 1 (upper right panels) and PSA 2 (lower right panels). These both exhibit a wave structure in the high latitude South Pacific that is reflected in both the T2m and SLP correlations, and that extend from Australia southward and eastward to southern South America. Both patterns also appear to impact the western hemisphere of Antarctica (see the T2m and Precipitation correlations). The MERRA-based and simulation-based correlations are generally quite similar, with neither showing a strong impact/connection with the tropics.

\subsubsection{Long-Term (Decadal Scale) Changes}


Figure 12 shows global maps of the differences between the means of the two 15-year periods (1995-2009) and (1980-1994) for JAS. The 250hPa height differences again (as during JFM) show for both MERRA and the simulations a general increase throughout the tropics and subtropics, with some hemispheric asymmetry in the sense that the increases extend further poleward to include much of the middle and high latitudes of the $\mathrm{NH}$. In the $\mathrm{SH}$ the maximum increases occur near $30^{\circ} \mathrm{S}$, while in the $\mathrm{NH}$ the maximum increase occurs near $60^{\circ} \mathrm{N}$. In contrast to JFM, there is no clear signature of a La Nina response (presumably because of the seasonal increase in the tropical Pacific easterlies). Instead, there is some evidence of an enhanced response over the Atlantic, reflecting a response to the warming of the Atlantic Ocean during this time period. In fact, the pattern of enhanced positive anomalies extending westward and poleward from the tropical Atlantic into the North and South Pacific oceans, and over Eurasia, is reminiscent of the response to an idealized uniform warming of the Indian Ocean (simulation not shown). The main differences between the MERRA pattern and that of the simulations is the more complex wavy structure in the MERRA 250hPa differences at middle and high latitudes, which likely reflects the larger sampling errors in the MERRA results.

There is little agreement between the model results and MERRA regarding the changes in weather statistics (Figure 12, second set of panels), with the MERRA difference patterns showing generally very little spatial coherence. The model results on the other hand do show coherence with generally reduced weather variability in the NH middle latitudes and in the $\mathrm{SH}$ near $30^{\circ} \mathrm{S}$ over the Pacific, and with increased weather variability over the high latitudes of both hemispheres. Both the model and MERRA show an increase in T2m over North America, central Asia, the Sahel and Australia. They disagree on the T2m temperature changes over central Africa and parts of South America, though it should be noted that these are regions where the MERRA reanalysis is not reliable. The precipitation differences also show little agreement between GPCP and the model, especially in the tropical Pacific.

Figure 13 further highlights the areas of agreement and disagreement among the MERRA and model difference fields. After removing the zonal mean the $250 \mathrm{hPa}$ differences are generally quite noisy, although there is some evidence of a wave response over the $\mathrm{SH}$ Pacific in both MERRA and the simulations. The zonal mean height differences show height increases above about $700 \mathrm{mb}$ that extend northward from about $30^{\circ} \mathrm{S}$. In MERRA the differences maximize near $200 \mathrm{hPa}$ and in the North Polar region, while in the simulations they continue to increase above $100 \mathrm{mb}$ with maximum values occurring near $60^{\circ} \mathrm{N}$.

The differences in the austral winter extremes between the two time periods are depicted in Fig. 14. Here again we present the differences in the number of heavy rain days, warm days and cold nights, though only for MERRA and the simulations (the limited number of observations in the $\mathrm{SH}$ do not allow reliable estimates of the differences in the extremes). The changes in the number of days with heavy precipitation show substantial 
SAM

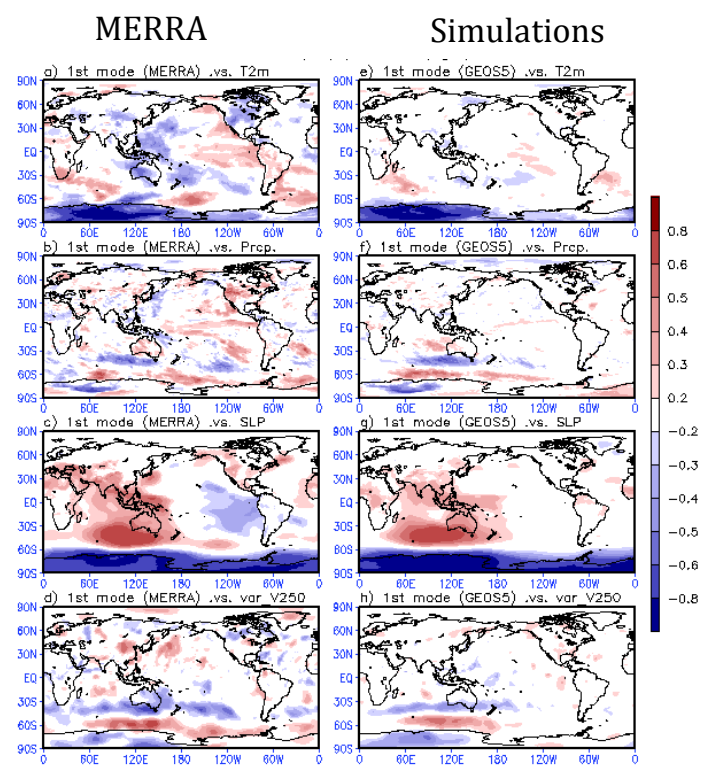

\section{Trend}

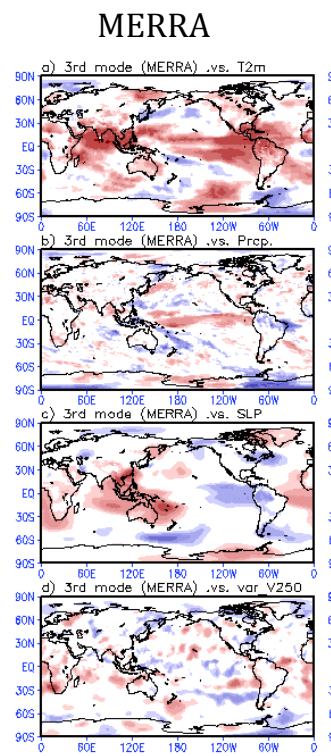

\section{Simulations}

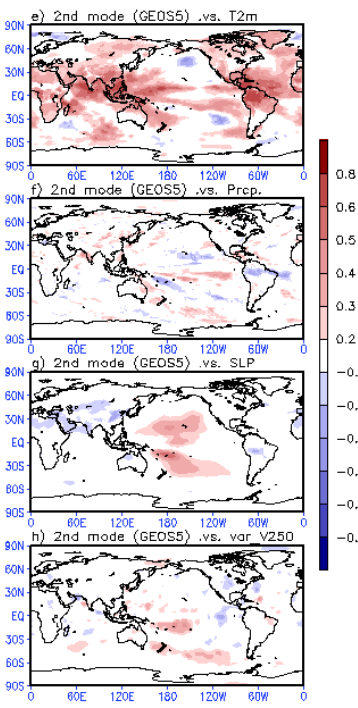

PSA 1

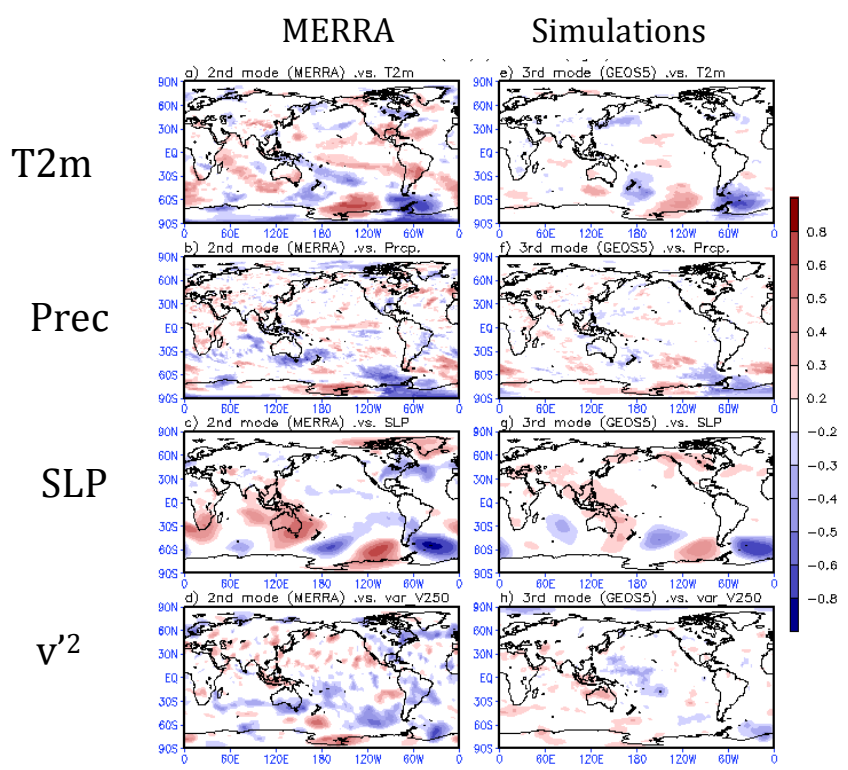

PSA 2

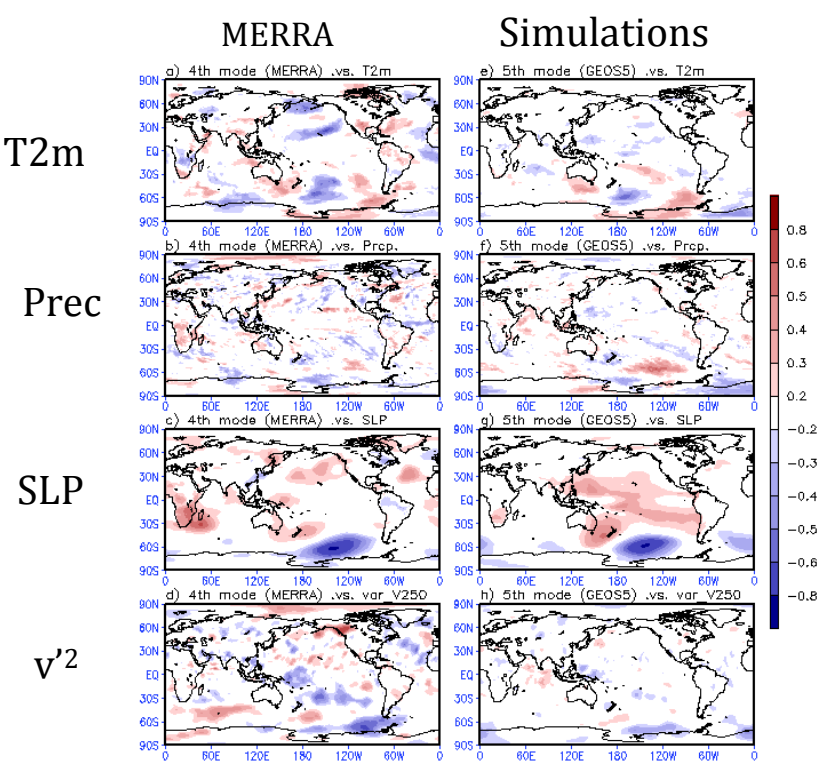

Figure 11: Correlations between the leading monthly REOFs (the corresponding PCsseasonally averaged) and seasonal mean $T 2 m$, precipitation, sea level pressure, and $250 \mathrm{hPa} \mathrm{v}$.2. For each set of panels, the results for MERRA are on the left and the results for GEOS-5 are on the right. Top left set of panels: MERRA REOF 1 and GEOS-5 REOF 1. Top right set of panels: MERRA REOF 2 and GEOS-5 REOF 3. Bottom left set of panels: MERRA REOF 3 and GEOS-5 REOF 2. Bottom right set of panels: MERRA REOF 4 and GEOS-5 REOF 5. Values are detrended before computing the correlations. The model results are the average of the correlations computed separately for each ensemble member. 
Observed

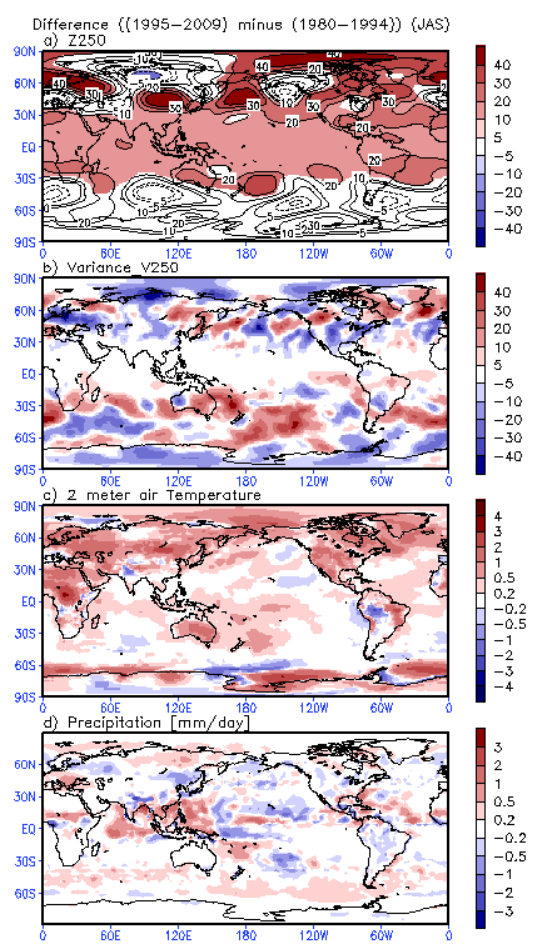

Simulated

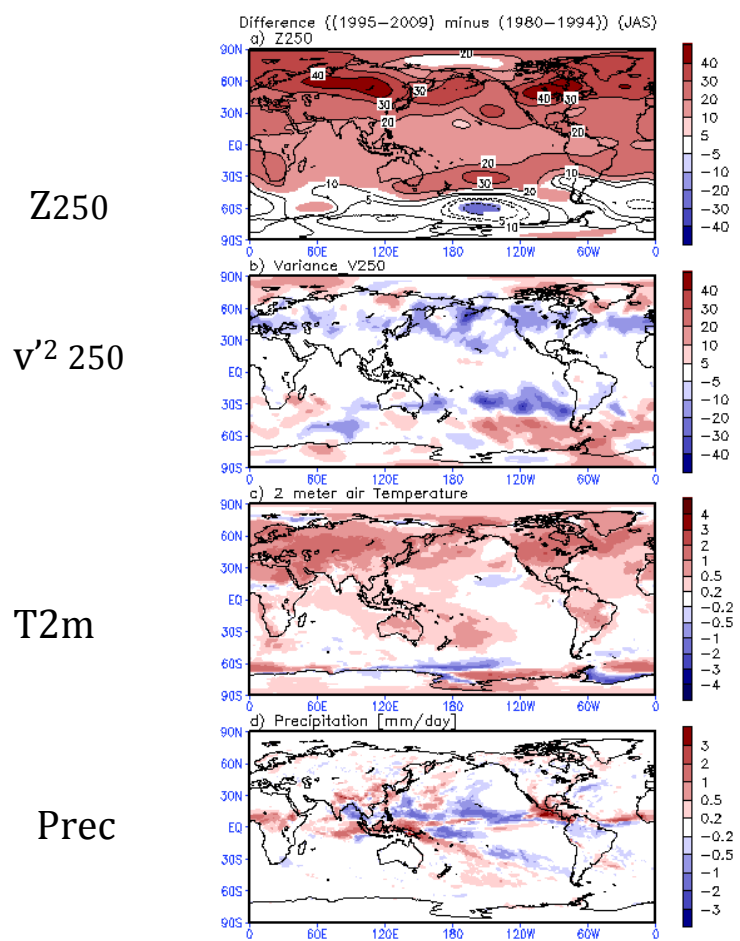

Fig. 12: The difference between the means of the two 15-year periods (1995-2009) and (19801994) for JAS. The left panels are for the observations (MERRA and GPCP precipitation) and the right panels are for the AMIP runs. Top panels are the $250 \mathrm{mb}$ height differences (only values significant at the 10\% level are shaded, units are meters), the second row consists of the differences in the $250 \mathrm{mb}$ daily $\mathrm{V}$-wind variance (units are $\mathrm{m} / \mathrm{s}$ squared), the third row shows the 2 meter temperature differences (units are ${ }^{\circ} \mathrm{C}$ ), and the last row shows the precipitation differences (units are $\mathrm{mm} /$ day).
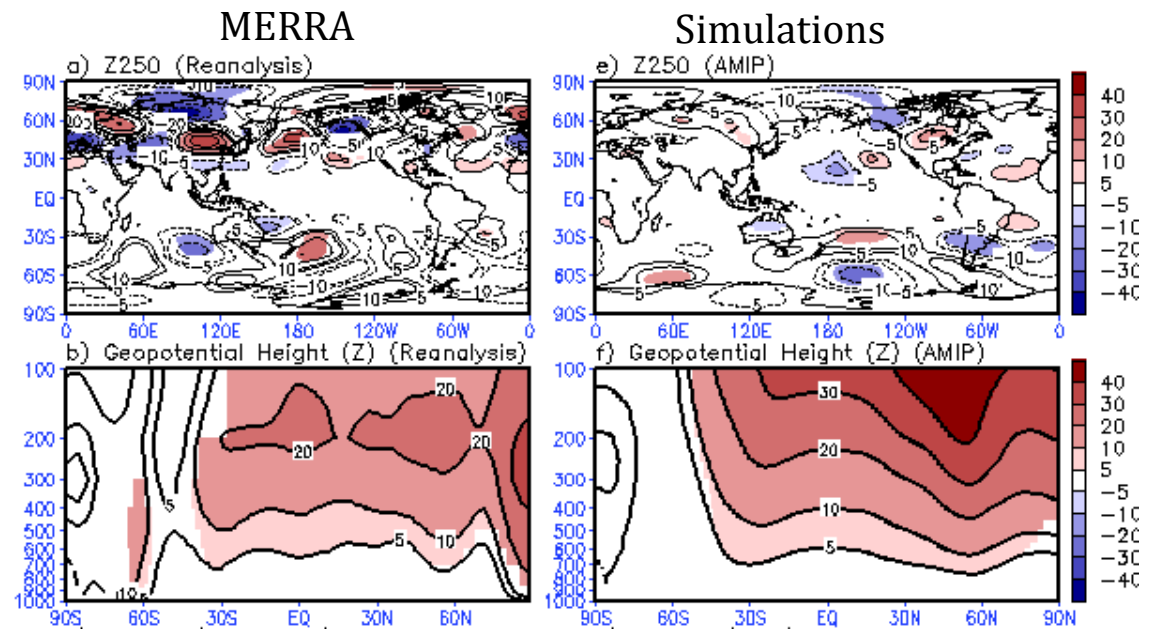

Fig. 13: The difference between the means of the two 15-year periods (1995-2009) and (19801994) for JAS. The left panels are for MERRA and the right panels are for the AMIP runs. Top panels are the $250 \mathrm{mb}$ height differences with the zonal mean removed, while the second row shows the zonal mean height differences (only values significant at the 10\% level are shaded, units are meters). 

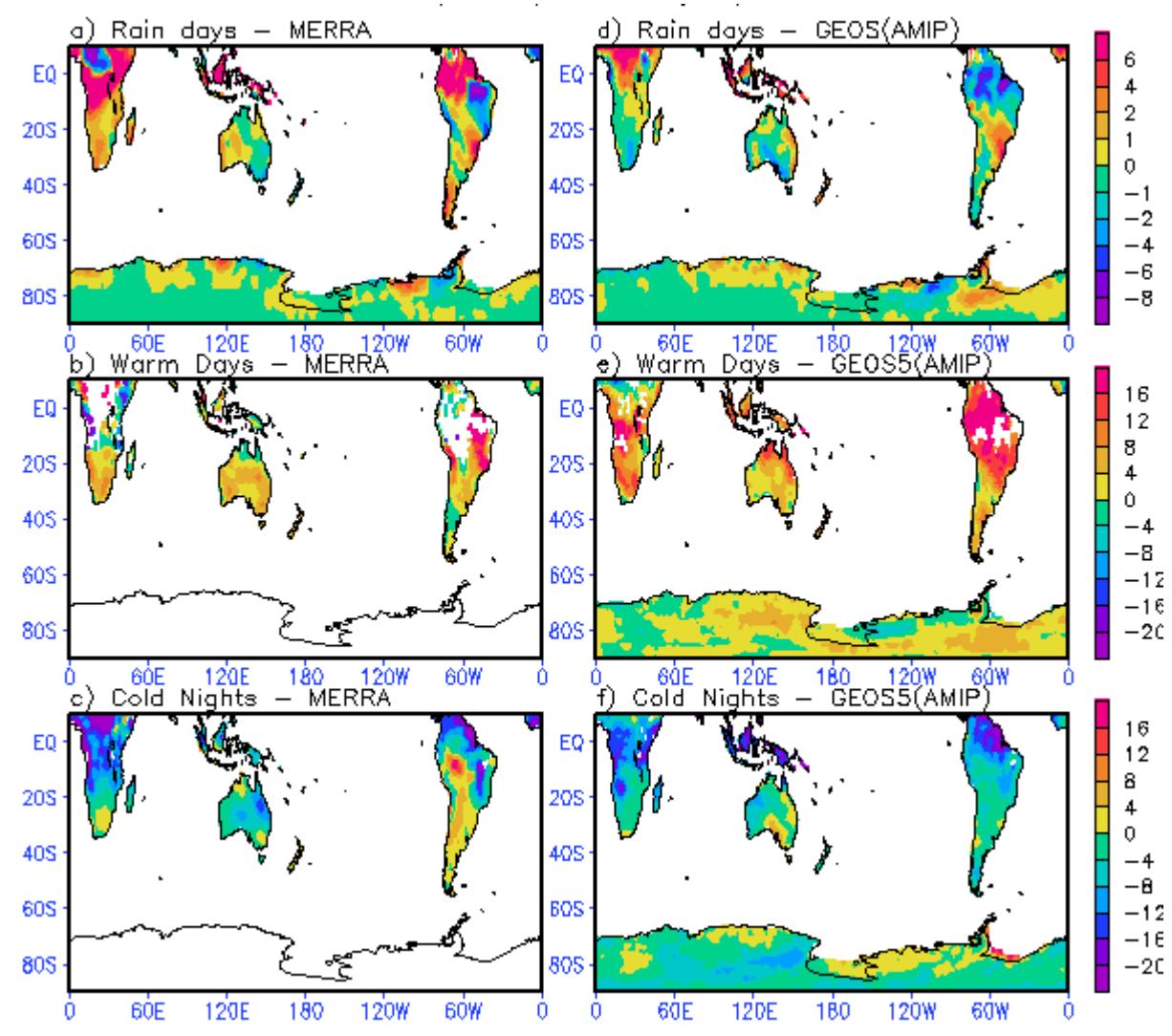

Fig. 14: The difference (JAS, 1995-2009 minus 1980-1994) in the 10-year return values of the number of heavy rain days ( $>5 \mathrm{~mm} /$ day), warm days (greater than the $90^{\text {th }}$ percentile of the daily maximum temperatures) and cold nights (less than the $10^{\text {th }}$ percentile of the daily minimum temperatures) for MERRA (left panels) and AMIP runs (right panels). Results are based on fits of the exceedances to a GPD.

differences between MERRA and the simulations with, for example, an increase over northern South America in MERRA and a decrease in the simulations. Both agree that there has been an increase in the number of heavy precipitation days in east-central South America and parts of Africa. Both the MERRA and the simulated temperature extremes are characterized by an increase in the number of warm days and a decrease in the number of cold days over much of the SH land masses with the largest changes occurring over northern South America, and Africa. Some of the major differences between MERRA and the simulations occur over central and southern South America, with MERRA showing an increase in the number of cold nights, while the simulations show a slight decrease.

Without observational estimates, the reliability of the simulated changes in the $\mathrm{SH}$ extremes is difficult to assess. While we do have the reanalysis estimates in the $\mathrm{SH}$, their quality is in question, since these too suffer from insufficient observational constraints on the precipitation and surface temperature fields, as well as from potential model bias. 


\subsection{Impact of $\mathrm{CO}_{2}$ Doubling and Uniform SST Increase}

We next turn to the analysis of more idealized simulations in which the model is forced with uniform increases in SST or doubled $\mathrm{CO}_{2}$. As already noted, these are not meant to provide realistic scenarios of future climate, but merely to assess sensitivities of the model climate and variability to such changes in such forcing, and to help provide some insight into the changes that have already occurred. These runs of course do not have ENSO or any other anomalous SST forcing, nor do they have any variations in trace gases or aerosols. Here our assessment of changes in variability is limited to any changes in internal atmospheric/land variability.

There are three different 20-year simulations consisting of a control run forced with a repeating annual cycle of the climatological (1981-2005 mean) SST, a run that is the same as the control but with doubled $\mathrm{CO}_{2}$, and another run that is the same as the control but with a globally uniform $2^{\circ} \mathrm{C}$ increase in SST. This change is large in the sense that that it is considerably greater than what has occurred in the last three decades. In particular, we note that the actual SST changes over the last three decades are generally less than $0.5{ }^{\circ} \mathrm{C}$ and are far from uniform (see for example the T2m changes in Figures 5 and 12; see also Deser et al. 2010). Also, the $\mathrm{CO}_{2}$ increase over the last 3 decades is approximately 14\%. Details of the experiments are provided in Appendix A. We begin by presenting the results for JFM. All model results are presented as differences from the control run.

\subsubsection{Boreal Winter (JFM)}

\subsubsection{Impact on the Mean Climate and Weather Variability}

\section{$\underline{\mathrm{CO}_{2}} \underline{\text { doubling }}$}

Some care must be taken in interpreting AGCM simulations with doubled $\mathrm{CO}_{2}$, since coupled IPCC model simulations show quite clearly that much of the global warming signal is realized as a warming of the oceans, and the atmosphere in turn responds to the associated changes in the SST. Nevertheless, it is instructive to try to isolate the fast response of the atmosphere and land to the change in radiative forcing, as discussed recently by $\mathrm{I}$. Held ${ }^{8}$ to see how much that might contribute to the continental warming.

The direct radiative impact (top left panels of Figure 15) on the atmosphere of doubling $\mathrm{CO}_{2}$ is a very modest warming of the troposphere with maximum zonal mean warming (between 0.2 and $0.5^{\circ} \mathrm{C}$ ) occurring at the tropopause (in the tropics and summer hemisphere) and the lower tropospheric Arctic, with cooling in the stratosphere (panel $a$ ). At the land surface, modest warming is largely confined to the northern middle latitudes (Figure 16, panel $a$ of bottom right panels). The tropospheric jets show a tendency to shift poleward (Figure 15). Changes in weather variability are small (order 10\%), with most of the main storm track regions showing some reduction in storm track activity

8 http://www.gfdl.noaa.gov/blog/isaac-held/2011/05/24/11-is-continental-warming-a-slave-to-warming-of-the-ocean-surface/\#more-1919 
(Figure 16, panel $a$ of top right panels). The Hadley Cell shows a slight weakening, and the main relative humidity changes are a small reduction $(<5 \%)$ in the tropics above $100 \mathrm{mb}$. Precipitation changes are small and unorganized, with some overall preference for reduced precipitation (Figure 16, panel $a$ of top right panels).

\section{Global $2^{\circ} \mathrm{C}$ increase in SST}

The impact of a uniform $2^{\circ} \mathrm{C}$ increase in the SST of the world's oceans (middle panels of Figure 15) consists of warming throughout the troposphere with maximum zonal mean warming of greater than $4^{\circ} \mathrm{C}$ occurring in the tropics just below the tropopause. Significant cooling is limited to the tropical and Arctic stratosphere. The relative humidity changes are positive at the tropopause and in the tropical troposphere, with reduced values in the extratropical troposphere (poleward of about $30^{\circ}$ lat) of both hemispheres. The zonal mean wind changes show a poleward and upward shift of the westerly jets, with anomalous easterlies in the upper tropical troposphere and the high latitudes of the Northern Hemisphere. The upper level troposphere height differences (Figure 16, panel $b$ of top left panels) show reduced heights at high latitudes resembling an enhanced positive phase of the annular modes (NAM and SAM) in both hemispheres. Surface warming exceeds $1^{\circ} \mathrm{C}$ over much of the world's land areas, with some regions showing increases of more than $3^{\circ} \mathrm{C}$ (Figure 16, panel $b$ of bottom right panels). The strength of Hadley Cell is reduced (Figure 15). The strength of the adjacent Ferrel Cells is also reduced in a way that is consistent with a poleward expansion of the Hadley Cell.

Precipitation changes (Figure 16, panel $b$ of bottom left panels) are mostly positive with increases occurring over the SPCZ, the tropical/subtropical southern Indian Ocean, on the northern fringe of the Pacific ITCZ, and the high latitudes (generally poleward of $60^{\circ}$ ) especially in the North Atlantic. Some reduction in precipitation occurs over South Africa, eastern Australia and central South America. The storminess (as measured by the variance of $200 \mathrm{hPa}$ daily v-wind) shows a well-defined poleward shift in both hemispheres (Figure 16, panel $b$ of top right panels).

The above results are compared (in the right panels of Figure 15) with the changes that were simulated to have occurred in the last three decades during JFM. The results show a weakening and poleward expansion of the Hadley that is consistent with observational studies (Fu et al. 2006). Such changes appear to be a robust response in coupled models to GHG forcing (Held and Soden, 2006; Lu et al. 2007, and have been linked to an increased tendency for long-term drought in the subtropics (e.g., Seager et al. 2007). The expansion of the Hadley Cell is associated with a poleward shift of the subtropical jets (e.g., Lu et al. 2007). The direct radiative impacts show similar features although these are likely too weak to contribute in a substantial way to the changes that have occurred in the last three decades. One thing of note is the substantial cooling in the $\mathrm{NH}$ stratosphere near the pole under $\mathrm{CO}_{2}$ doubling, which may contribute to the observed changes in that region. Whether any of the observed continental interior warming is at all the result of the fast response to $\mathrm{CO}_{2}$ changes on the land surface is not clear, though any such impact would again be small. Overall, the impacts of a $\mathrm{CO}_{2}$ doubling presented here 

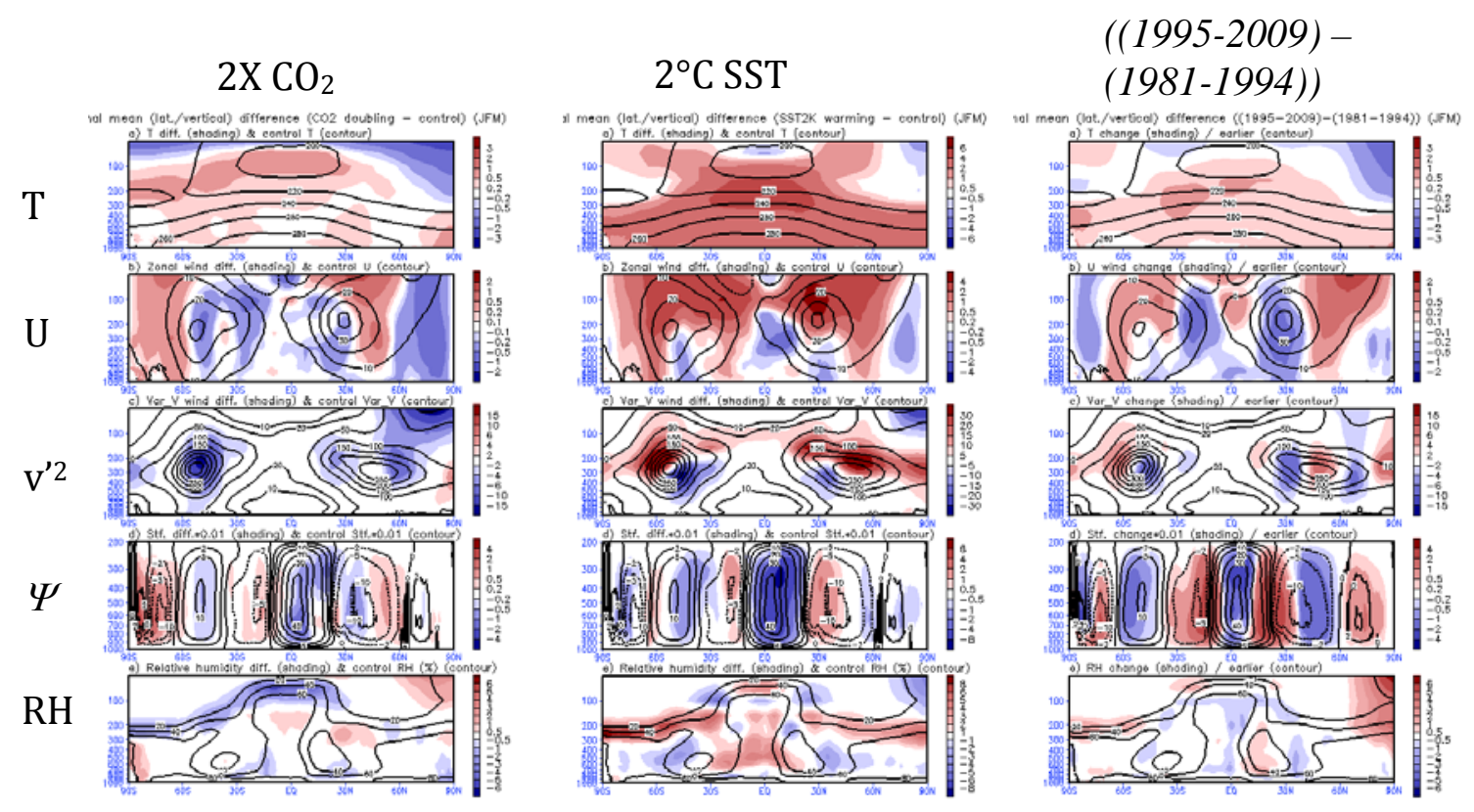

Figure 15: JFM zonal mean differences (shaded) between experiment and control for temperature, zonal wind, variance in $v$ (6hrly), meridional stream function ( $\Psi)$, and relative humidity. Left panels: double $\mathrm{CO}_{2}$; middle panels: global $2^{\circ} \mathrm{C}$ increase in $\mathrm{SST}$. Contours are the mean control values. The right panels show the ensemble mean difference ((1995-2009) - (1981-1994)) fields (shaded) from the three AMIP simulations. The contours are the mean of the period (1981-1994). Note the smaller contour intervals for the double $\mathrm{CO}_{2}$ run and observed changes.

appear to be consistent with those presented by I. Held ${ }^{8}$ based on the Geophysical Fluid Dynamics Laboratory (GFDL, AM2.1/LM2.1) AGCM. Evidence for the predominantly oceanic control of the recent world-wide warming over land can be found in Compo and Sardeshmukh (2009).

\subsubsection{Impact on Climate Variability}

In view of the considerable world-wide impact of the leading modes of variability, it is of interest to determine whether they are impacted (either as a change in amplitude or spatial structure) by changes in $\mathrm{CO}_{2}$ or SST. Hu et al. (2011) addressed this issue in a comparison of IPCC scenario A1B and control runs with the CCSM3 model. They found that the leading seasonal mean modes of internal variability are largely unaffected by an increase in GHG and aerosol concentrations.

Our results are consistent with Hu et al. in that the leading modes of variability found in the AMIP runs and MERRA (in particular, the NAM, NAO and PNA) exist also in the control and other idealized fixed forcing runs. Of course the atmospheric ENSO mode does not appear since it is a response to SST anomalies. In fact, we have computed the REOFs separately for each experiment and found only minor differences in the patterns (differences that are likely well within the sampling errors). In order to assess any potential changes in variability, we have computed the REOFs from the combined set of 
3 runs (first removing the means of the individual runs separately), to obtain a combined set of REOFs (left panels of Figure 17). This shows that the NAM, NAO and PNA are the three leading modes, with the fourth mode resembling the North Pacific Oscillation (NPO, also found in the AMIP runs and MERRA as a higher mode - though not discussed in the previous sections). The NPO is well known as an important pattern of subseasonal variability (e.g., Linkin and Nigam 2007). The panels on the right of Figure 17 show scatterplots of the amplitudes of the 4 leading PCs. These show no obvious differences in the variability in the various runs. Table 1 , however, suggests that the variability of the NAM increased by about $2 / 3$ and the variability of the NPO decreased by about $1 / 2$, in the $2^{\circ} \mathrm{C}$ SST run. Also, it appears that the PNA variance decreased by about $1 / 2$ in the doubled $\mathrm{CO}_{2}$ run. It should however be emphasized that with just 20 years for each experiment the above results are only marginally significant at the $5 \%$ level (based on a F-test for the ratio of variances).
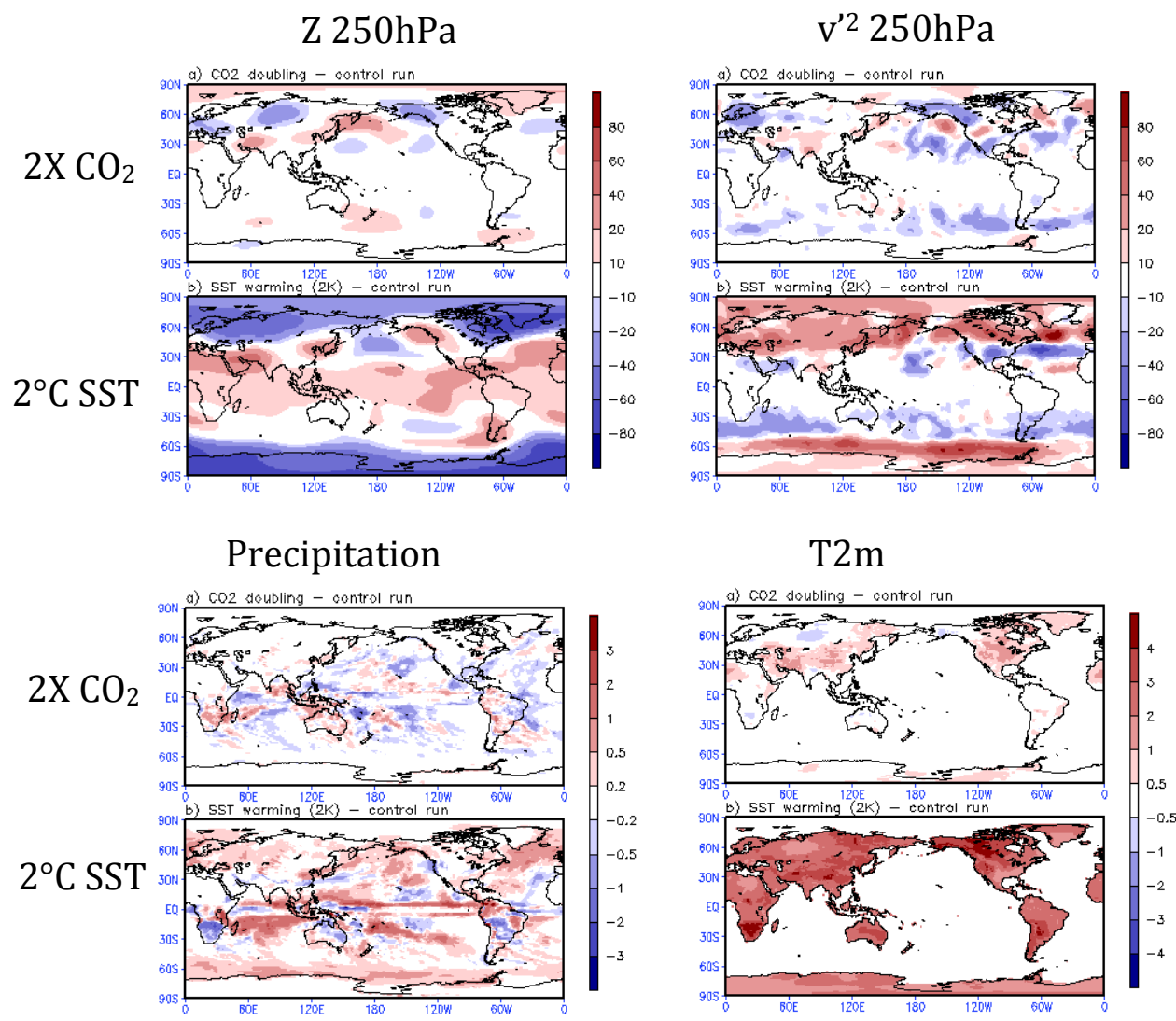

Figure 16: JFM differences from the control run and the experiments with (a) double $\mathrm{CO} 2$, and b) $2{ }^{\circ} \mathrm{C} \mathrm{SST}$ increase. The top left panels show the 250hPa height (meters, with the global means removed: these are 10532, 10540, and 10651 meters for the control, double $\mathrm{CO}_{2}$ and $2^{\circ} \mathrm{C} \mathrm{SST}$ runs, respectively). The top right panels show the $250 \mathrm{mb} \mathrm{v}{ }^{22}$ $\left(\mathrm{m}^{2}\right)$. The bottom left panels show the precipitation ( $\mathrm{mm} /$ day), and the bottom right panels show the $\mathrm{T} 2 \mathrm{~m}\left({ }^{\circ} \mathrm{C}\right)$. 

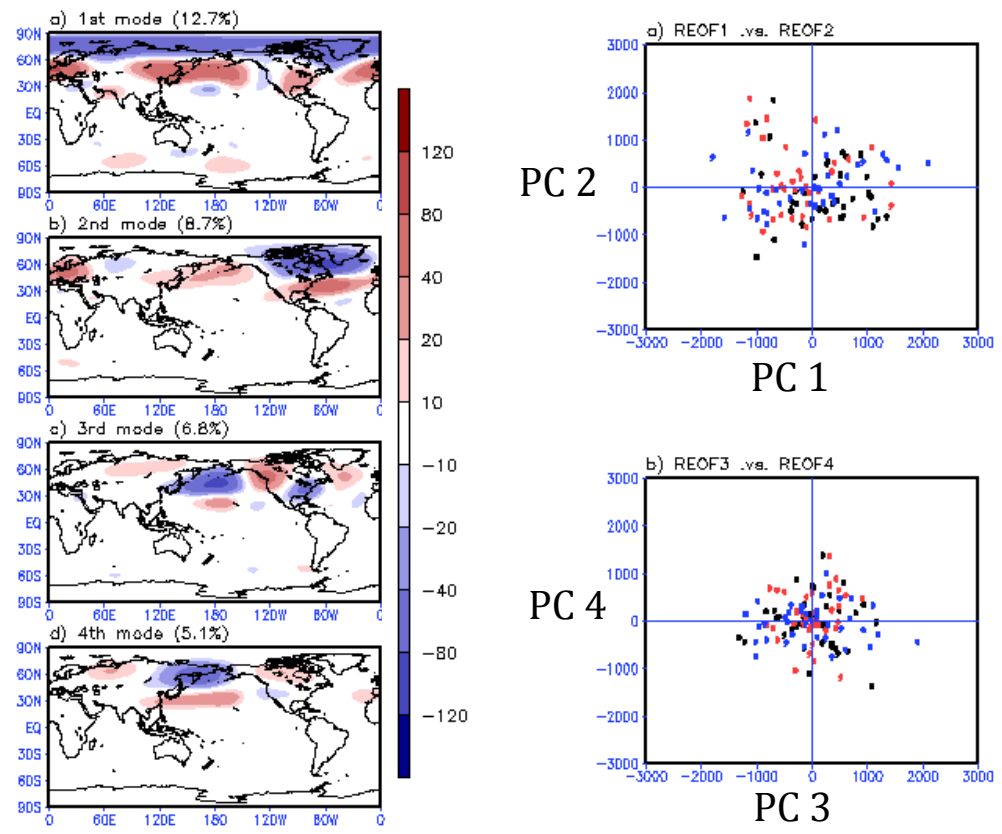

PC 1

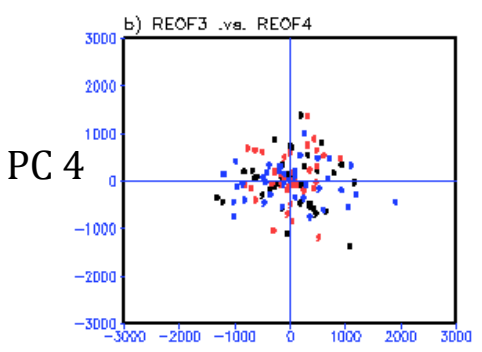

PC 3

Figure 17: Left panels: Leading monthly JFM 250hPa height REOFs of the combined control, $2{ }^{\circ} \mathrm{C}$ SST increase, and double $\mathrm{CO}_{2}$ runs. The anomalies are computed with respect to the means of the individual runs. Right panels: Scatterplots of the leading REOFS (the principal components, PCs). Black dots: control run. Red dots: double CO2 run. Blue dots: $+2{ }^{\circ} \mathrm{C}$ SST run.

Table 1: JFM Variances (X 100,000) of the 4 leading REOFs in the idealized experiments. Values in bold are significantly different from the control at $5 \%$.

\begin{tabular}{|l|l|l|l|}
\hline & CONTROL & $\mathbf{2 X C O}_{2}$ & $\mathbf{S S T}+\mathbf{2}^{\circ} \mathbf{C}$ \\
\hline MODE 1 & 3.00 & 3.05 & $\mathbf{4 . 9 8}$ \\
\hline MODE 2 & 2.77 & 2.93 & 1.99 \\
\hline MODE 3 & 1.96 & $\mathbf{1 . 0 2}$ & 3.10 \\
\hline MODE 4 & 1.84 & 1.72 & $\mathbf{0 . 9 6}$ \\
\hline
\end{tabular}

We next turn to the impacts on the JAS climate and variability.

\subsubsection{Austral Winter (JAS)}

\subsubsection{Impact on Mean Climate and Weather Variability}

$\underline{\mathrm{CO}_{2}} \underline{\text { doubling }}$

The direct radiative impact on the atmosphere of doubling $\mathrm{CO}_{2}$ during JAS (top left panels of Figure 18) is in many ways quite similar to the response during JFM, although 
with the hemispheres reversed. The impacts on the temperature and zonal winds are somewhat stronger than for JFM, with more extensive zonal mean warming in the Northern Hemisphere, greater cooling in the SH polar stratosphere, and larger changes (poleward and upward shift) in the zonal wind in the Southern Hemisphere. The Hadley cell changes are small. The largest changes in $\mathrm{RH}$ are negative in the tropical tropopause and positive in the Antarctic stratosphere (compared to the Arctic stratosphere for JFM). The 250hPa height differences (top left panel of Figure 19) are more coherent than for JFM with generally enhanced heights in the high latitudes (north of $45^{\circ} \mathrm{N}$ ) of the $\mathrm{NH}$, and reduced heights over the high latitudes (south of $60^{\circ} \mathrm{S}$ ) of the $\mathrm{SH}$. Modest surface warming again occurs over much of the extratropical land area but it is more extensive over Russia (panel $a$ of the lower right panels of Figure 19). Changes in storminess (panel $a$ of the upper right panels of Figure 19) again show a general reduction especially in the $\mathrm{NH}$ middle latitudes.

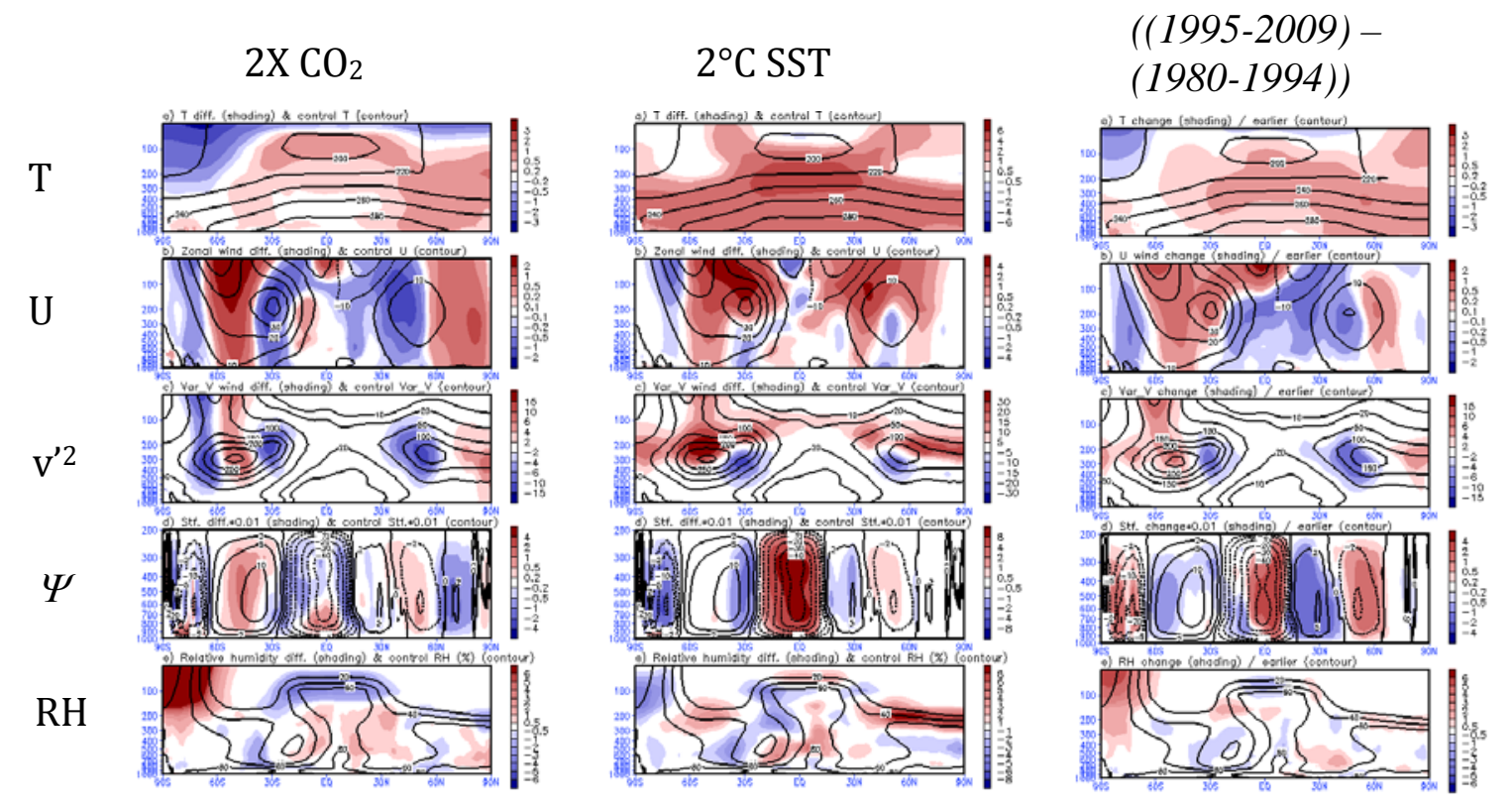

Figure 18: JAS zonal mean differences (shaded) between experiment and control for temperature, zonal wind, variance in $v$ (6hrly), meridional stream function( $\Psi)$, and relative humidity. . Left panels: double $\mathrm{CO}_{2}$; middle panels: global $2^{\circ} \mathrm{C}$ increase in $\mathrm{SST}$. Contours are the mean control values. The right panels show the ensemble mean difference ((1995-2009) - (1980-1994)) fields (shaded) from the three AMIP simulations. The contours are the mean of the period (1980-1994). Note the smaller contour intervals for the double $\mathrm{CO}_{2}$ run and observed changes. 

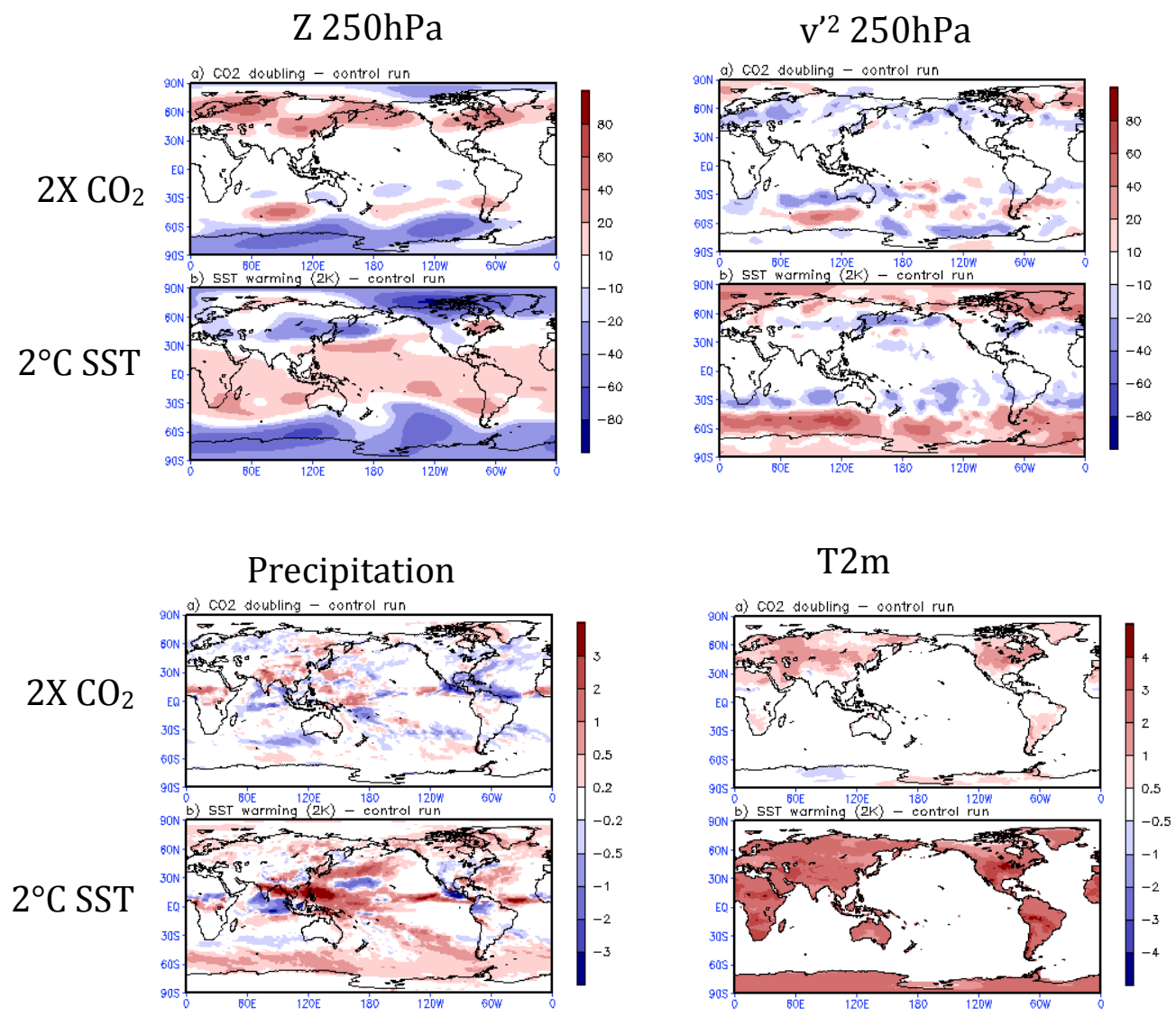

Figure 19: JAS differences from the control run and the experiments with (a) double $\mathrm{CO} 2$, and $b$ ) $2{ }^{\circ} \mathrm{C}$ SST increase. The top left panels show the 250hPa height (meters, with the global mean removed: these are 10627, 10639, and 10748 meters for the control, double $\mathrm{CO}_{2}$ and $2^{\circ} \mathrm{C}$ SST runs, respectively). The top right panels show the $250 \mathrm{mb} v^{2}$ $\left(\mathrm{m}^{2}\right)$. The bottom left panels show the precipitation ( $\mathrm{mm} /$ day), and the bottom right panels show the $\mathrm{T} 2 \mathrm{~m}\left({ }^{\circ} \mathrm{C}\right)$.

\section{Global $2^{\circ} \mathrm{C}$ increase in SST}

The zonal mean impact of a uniform $2^{\circ} \mathrm{C}$ increase in the SST of the world's oceans (middle panels of Figure 18), are quite similar to that already shown for JFM, including a general warming throughout the troposphere, an upward and equatorward expansion of the upper level westerlies, enhanced $\mathrm{v}^{2}$ above the climatological maxima accompanied by a reduction equatorward and below the climatological maxima, a reduction in the strength of the Hadley Cell, and RH increases near the tropopause. The spatial maps of the changes (panel $b$ of Figure 19), show an upper level height response with reduced heights in both polar regions, and enhanced heights equatorward of about $30^{\circ}$ latitude (again, having a zonally symmetric component that is reminiscent of the positive phase of the annular modes). Surface warming is wide spread over all land areas with some of the largest warming occurring over the U.S. Great Lakes region. Precipitation changes are generally positive in the tropical regions of the ITCZ and the Pacific warm pool extending westward across southern Asia. 

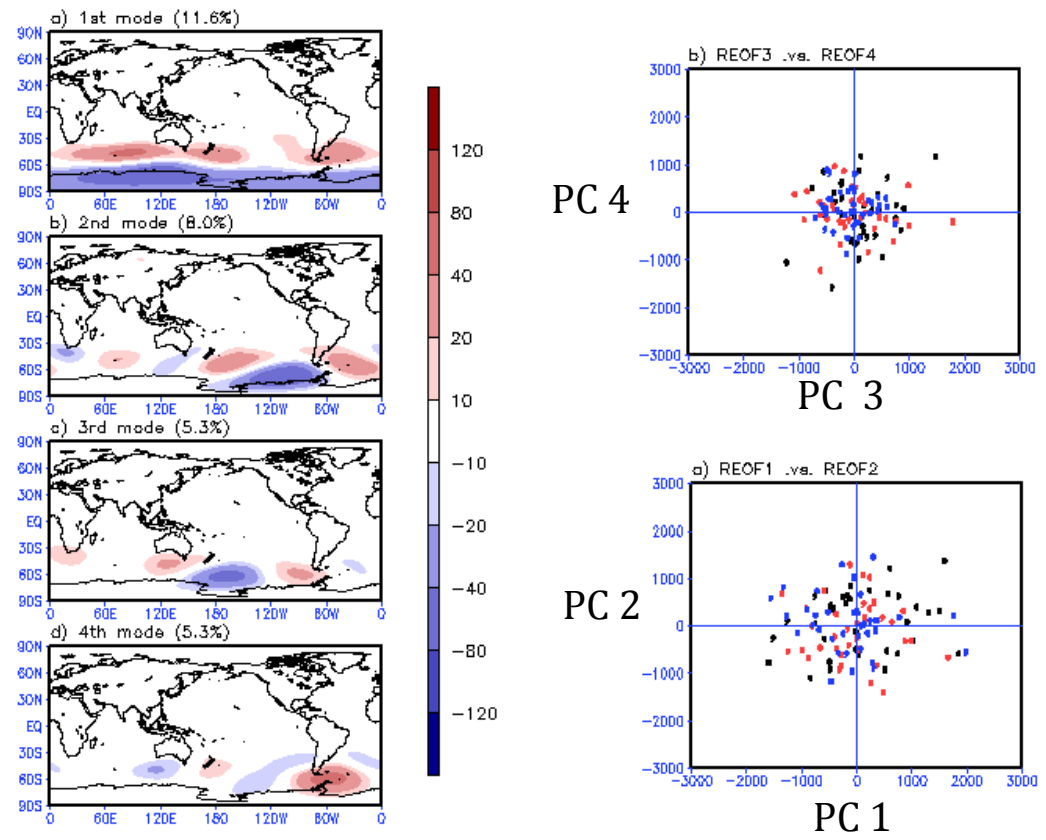

Figure 20: Left panels: Leading monthly JAS 250hPa height REOFs of the combined control, $2^{\circ} \mathrm{C}$ SST increase, and double CO2 runs. The anomalies are computed with respect to the means of the individual runs. Right panels: Scatterplots of the leading REOFS (the principal components, PCs). Black dots: control run. Red dots: double CO2 run. Blue dots: $+2{ }^{\circ} \mathrm{C}$ SST run.

The above results are compared (in the right panels of Figure 19) with the changes that were simulated to have occurred in the last three decades during JAS. The comparison indicates that the weakening of the Hadley Cell that has occurred in the last three decades during JAS (just as for JFM) is consistent with observational studies (Fu et al. 2006), and as already noted above, appears to be a robust response in coupled models to GHG forcing (Held and Soden, 2006; Lu et al. 2007). Also, the expansion of the Hadley Cell is associated with a poleward shift of the subtropical jets as discussed in Lu et al. (2007). The asymmetrical warming (mostly occurring in the NH in the zonal mean) is, in contrast, more similar to what can be expected from the direct radiative impacts of a doubling in $\mathrm{CO}_{2}$. Also, the cooling in the $\mathrm{SH}$ polar stratosphere, the reduction in $\mathrm{RH}$ in the tropical tropopause and the increase in the polar stratosphere are consistent with the direct radiative impacts of the increase in $\mathrm{CO}_{2}$.

\subsubsection{Impact on Climate Variability}

The leading internal SH modes found in the AMIP runs and MERRA (Figure 10) are largely unchanged in the control and other idealized forcing runs. This includes the SAM, and the two PSA modes (Figure 20). The trend mode does not appear as expected since there is no external time varying forcing. Table 2 suggests that there are only modest 
changes in the variance of the internal modes. The $\mathrm{CO}_{2}$ increase appears to decrease the variance of the SAM by about $40 \%$, while the SST warming acts to reduce the variability of PSA modes.

Table 2: JAS Variances (X 100,000) of the 4 leading REOFs in the idealized experiments. Values in bold are significantly different from the control at the 5\% level.

\begin{tabular}{|l|l|l|l|}
\hline & CONTROL & $\mathbf{2 X C O}_{2}$ & $\mathbf{S S T}^{\circ}{ }^{\circ} \mathbf{C}$ \\
\hline MODE 1 & 4.27 & $\mathbf{2 . 5 2}$ & 3.22 \\
\hline MODE 2 & 2.39 & 2.39 & 2.09 \\
\hline MODE 3 & 1.60 & 2.06 & $\mathbf{0 . 8 7}$ \\
\hline MODE 4 & 2.52 & $\mathbf{1 . 1 4}$ & $\mathbf{0 . 8 7}$ \\
\hline
\end{tabular}

\subsection{Summary and Discussion}

Weather extremes are inextricably linked to variability on a broad range of time scales. As such, understanding the causes of any changes in the characteristics of weather extremes requires an understanding of the connections between extremes and climate variability. This was addressed here in the framework of AMIP-style simulations in which the model was forced with observed SSTs, GHGs and ozone. In particular, we have reviewed the ability of the GEOS-5 AGCM, run at moderately high horizontal resolution $(50 \mathrm{~km})$, to simulate the major modes of monthly climate variability and weather extremes in the two winter hemispheres during the period 1980-2009. We also examined the nature of the longer-term (decadal) changes that occurred during this time period, including the changes in extremes. Idealized AGCM experiments were used to help guide the interpretation of the results.

Several questions were posed in the Introduction that we now attempt to answer. Specifically:

Does the GEOS-5 model reproduce the observed winter climatological fields?

In short, the results show quite clearly, that the GEOS-5 AGCM when forced by the observed SST and GHGs and ozone does reproduce the (1980-2009 mean) climatological fields quite well, including the stationary waves and precipitation fields in both winter hemispheres.

Does it have the correct low-frequency (monthly mean) modes of variability?

The GEOS-5 model appears to do a credible job in reproducing the observed variability, with several caveats. The model overestimates the monthly mean precipitation variability in the tropics. It also overestimates the upper tropospheric height variability in the North Pacific during JFM. The model does a remarkably good job in reproducing the leading patterns of monthly variability in both winter hemispheres. These include the 
ENSO response, the PNA, NAO, NAM, SAM and two Pacific South American (SPA) patterns. In addition, the model reproduces the key trend modes during both seasons. The main deficiency appears to be a too strong PNA variability (hence too much variability in the North Pacific) that appears to reflect a too strong sensitivity of the atmosphere to SST forcing in the central tropical Pacific.

Having multiple ensemble members also allowed an assessment of the degree to which the various modes are constrained by external forcing (SST, GHG and ozone). The results show a strong forcing for the trend and ENSO modes, while the lack of correlation between the individual ensemble members for the other modes indicates that these are largely internal to the atmosphere (unforced). This is confirmed with the idealized control simulation (having no interannual variations in external forcing) that reproduced the leading modes (PNA, NAO, NAM, SAM, and PSA). There is some evidence that the PNA is impacted/modulated by SST at longer time scales, and that appears to contribute to the tendency for a La Nina - like (negative PNA) response over the United States during the last three decades. Trends in other modes (for example those identified in previous studies of the NAO, NAM and SAM) emerge only in the context of longer records and/or during the warm season.

\section{Does it have the correct weather variability and extremes?}

The model reproduces the spatial structure and amplitude of the JFM and JAS winter storms tracks. Over land, the model also reproduces the basic patterns and amplitudes of precipitation extremes over the winter hemispheres, as reflected in the 10-year return values of the daily precipitation maximum and the warmest day and warmest night. The model does however tend to overestimate precipitation maxima at low latitudes especially during JAS, and suffers from a substantial day time cold bias in high latitude land areas during JFM. Efforts to validate the simulated daily extremes, are hampered by missing data, especially for the temperature record. The problem is especially severe in the SH where reasonably good coverage is largely confined to Australia.

\section{Are the linkages between climate variability and regional weather simulated correctly?}

The model does a remarkably good job of reproducing the predominant teleconnections associated with ENSO, the NAO, PNA, NAM, SAM and SPA modes. This includes the changes over the US associated with ENSO (e.g., enhanced storminess and precipitation along the US Gulf States), over Australia, New Zealand and Antarctica associated with the SAM, and over Eurasia associated with the NAM and NAO. It also includes warmer (colder) temperatures over northern Eurasia (the Mediterranean and North African regions) during a positive NAM, the increased storminess and warming over northern Europe and the warming over the US eastern seaboard during a positive NAO, and the warming over Alaska and western Canada during a positive PNA.

What are the longer-term changes that have occurred over the last three decades and are these reproduced in the model? 
There is a very clear trend towards more positive upper tropospheric heights throughout the tropics and subtropics (extending into much of the middle latitudes) during the austral winter in both MERRA and the model simulations. During the boreal winter (JFM) the positive trend is again evident in the height field but it is intermingled with a strong ENSO signal in both the MERRA and simulations. The ENSO component of the trend appears to favor stronger warm events and contributes to an overall warming in the tropics and subtropics. As mentioned above, there is however imbedded in the warming trend, a La Nina-like (negative PNA) pattern. This is associated with a northward shift in the storm tracks and warmer temperatures over the United States. The relationship between these two distinctly different behaviors of a tendency towards both an El Nino like general atmospheric warming, and an embedded trend toward a La Nina like atmospheric response is unclear, but the latter appears to reflect the long-term response of the PNA (an intrinsically internal mode of monthly variability) to the cooling of the central and eastern tropical Pacific over the last three decades. One possibility is that this reflects the apparent shift from eastern to central Pacific ENSOs (e.g., Ashok et al. 2007), resulting in a greater sensitivity of the PNA to the cooler Pacific in recent years.

During JFM the model shows a distinct surface warming over northern Asia that, in the reanalysis, is a region of slight cooling over the last three decades. Other discrepancies between the reanalysis and the model during JFM occur in the polar regions, where the reanalysis shows a negative height change over the Southern Hemisphere and a positive change in the Northern Hemisphere, that are not reproduced in the simulations. The extent to which these represent true trends (that are not reproduced by the model) or whether they are simply statistical residuals of the variability associated with the SAM and the NAM is not clear. It is noteworthy that, despite these discrepancies, both the reanalysis and simulations show a zonally-symmetric poleward shift in the SH storm tracks during JFM.

During JAS, the model and reanalysis are consistent in showing warmer surface temperatures throughout North America, central Eurasia, Australia, and northern Africa. There is little consistency in the changes in the storm tracks, with the reanalysis showing little spatial coherence in the changes, while the model shows a poleward shift in the SH and a general reduction in storminess over the NH middle latitudes. Similarly, there is no agreement in the changes in the zonal mean jets. These results highlight the lack of dominant teleconnections and associated SST-forced changes in planetary waves during JAS, with the general continental warming presumably induced by the warmer oceans as discussed previously.

The observed and simulated changes in boreal winter extremes between the two periods reflect the continental warming and, over North America, the La Nina (negative PNA) response, including the northward shift of the storm tracks and the generally warmer conditions over the southern US. In particular, much of the southern United States shows a decrease in the number of days with heavy precipitation, while much of Europe and eastern Russia show an increase. Much of southern and central Asia, the Mediterranean region, and the southern US are characterized by an increase in the number of warm days. The major discrepancy between the simulations and observations is that the latter show a 
reduction in the number of warm days (and an increase in the number of cold days) in northern Russia while the simulations produce the opposite, although the substantial number of missing observations in the recent decade make the observational results unreliable in that region. The simulated austral winter temperature extremes show an overall increase in the number of warm days and a decrease in the number of cold days over much of the SH land masses with the largest changes occurring over northern South America, southern Africa and northern Australia. The simulated changes in the number of days with heavy precipitation is more complicated showing for example a reduction over the Amazon basin, and an increase over equatorial Africa. The reliability of the simulated changes in the SH extremes is however unclear, since the observationallybased estimates suffer from limited data coverage and uncertainties in the quality of the reanalysis data.

What can idealized AGCM experiments tell us about the recent, and possible future changes in climate variability and weather extremes?

During JFM, the warming of the world's oceans by $2^{\circ} \mathrm{C}$ leads to several key changes, including a poleward shift in the storm tracks, a poleward and upward shift in the middle latitude jets, a weakening and poleward expansion of the Hadley Cell, and a general warming over land that in some regions exceeds $3^{\circ} \mathrm{C}$. The direct radiative impact on the atmosphere of a $\mathrm{CO}_{2}$ doubling is weak, showing a maximum warming $\left(>1^{\circ} \mathrm{C}\right)$ near the tropical and SH tropopause, a cooling above the tropopause, especially in the $\mathrm{NH}$ high latitudes, a weak poleward shift in the middle latitude jets (approximately $0.5 \mathrm{~m} / \mathrm{s}$ change), and continental interior warming of up to $1^{\circ} \mathrm{C}$ in the $\mathrm{NH}$. Comparisons with the simulated changes of the last three decades suggests that the expansion and weakening of the Hadley Cell is consistent with the impact of the SST warming, as is the observed SH poleward shift in the subtropical jet and storm tracks, and the continental warming.

During JAS the uniform SST increase also produces a poleward shift in storminess, an upward shift in the middle latitude jets, a weakening and poleward expansion of the Hadley Cell, and a general warming of the continents. The direct radiative impact on the atmosphere of a $\mathrm{CO}_{2}$ doubling is again weak, showing the largest warming $\left(>0.5^{\circ} \mathrm{C}\right)$ occurring near the tropical tropopause and in the $\mathrm{NH}$ middle and high latitude troposphere, together with an interior continental surface warming of up to $1^{\circ} \mathrm{C}$ in the $\mathrm{NH}$. Cooling occurs in the stratosphere, especially in the SH high latitudes. A comparison with the simulated changes of the last three decades indicates that the weakening of the Hadley Cell is again (as during JFM) consistent with the response to the uniform SST increase. That is also true for the SH poleward shift of the subtropical jets and storm tracks, while the NH changes in the jet and storm tracks are less clearly linked to the SST changes. In fact, the asymmetrical warming (mostly occurring in the $\mathrm{NH}$ in the zonal mean) is similar in pattern to the direct radiative impact of increases in $\mathrm{CO}_{2}$. Also, the reduction in $\mathrm{RH}$ in the tropical tropopause and the increase in the upper level south polar region is consistent with the direct radiative impacts of an increase in $\mathrm{CO}_{2}$. 


\section{Concluding Remarks}

The climate community is being challenged to provide increasingly more comprehensive societally-relevant information about the impacts of climate change that go well beyond broad statements about how much the global mean temperature will change. This in turn requires increasingly more comprehensive assessments of the quality of climate models to reproduce past regional climate impacts as well as the full spectrum of observed climate variability including those aspects (such as weather extremes) that are likely to have the greatest impact on society.

Our analysis shows that the wintertime climate and weather variability and trends of the last three decades are comprised of a rich assortment of internal (to the atmosphere) and externally forced (SST, GHGs, ozone) modes that have profound impacts on regional climates on monthly and longer time scales. Any assessment of long-term changes, including changes in extremes, must take these modes into account. In particular, we found that the long-term warming trends of the last three decades are intertwined with ENSO and the PNA. In addition, our more idealized runs highlight the important role of the oceans in warming the continents, as well as their controls on other key climate features such as the Hadley Cell, subtropical jets and storm tracks. Those runs also show that the spatial structure of the leading internal modes of variability is largely unchanged, even with substantial changes in external forcing.

Our assessment of the GEOS-5 model AMIP simulations indicates that the model is of sufficient quality to provide realistic assessments of the wintertime impacts of long-term changes in SST and GHGs on regional climates and weather extremes. Gaps in the observational coverage and the uncertain quality of the reanalysis data, however, hinder our ability to validate the model results over much of the SH and parts of Asia, especially for assessing changes in the extremes.

We did not include the warm and transition seasons in our analysis because we believe current climate models do not provide sufficiently realistic representations of such basic features as warm season continental precipitation, including the diurnal cycle and mesoscale convective systems that are critical to achieving realistic summer climates. Nor do they adequately resolve the most intense tropical storms that are in some regions the most important extreme events in terms of their impacts on society. In part, this is a resolution issue, although some necessary model improvements will likely still require better parameterizations, at least for the resolutions that are expected to be feasible for climate models during the next decade. 


\section{Appendix A}

\section{The GEOS-5 Model and Experiments}

The NASA Goddard Earth Observing System (GEOS-5) Atmospheric General Circulation Model or AGCM (Rienecker et al., 2008) employs the finite-volume dynamics of Lin (2004). This dynamical core is integrated with various physics packages (Bacmeister et al., 2006) under the Earth System Modeling Framework (Collins et al., 2005) including the Catchment Land Surface Model (Koster et al., 2000), and a modified form of the Relaxed Arakawa-Schubert convection scheme described by Moorthi and Suarez (1992). For the experiments described here we used version 2.4 of the AGCM. The model was run with 72 hybrid-sigma vertical levels extending to $0.01 \mathrm{hPa}$, and $1 / 2^{\circ}$ (about $50 \mathrm{~km}$ ) horizontal resolution on a latitude/longitude grid. Atmospheric variables and surface variables were output every 6 hours, and for some variables (in particular those with a strong diurnal cycle) every 3 hours.

In addition to the atmospheric model inter-comparison (AMIP) style runs forced with observed SST, several other more idealized experiments were run with a repeating climatological annual cycle in the SST and sea ice. These include a control, a run with a uniform $2^{\circ} \mathrm{C}$ increase in the global SST, and a run with doubled $\mathrm{CO}_{2}$ (Table 1)

For the AMIP runs, $\mathrm{CO}_{2}$ consists of the time varying annual global mean values provided by IPCC/CMIP5. The other greenhouse gases (GHGs: CH4, N2O, CFC-11, CFC-12, and HCFC-22), stratospheric water vapor $(\mathrm{H} 2 \mathrm{O})$, and ozone $\left(\mathrm{O}_{3}\right)$ are relaxed to time varying zonal averages with a two-day e-folding time. The zonal averages of the GHGs are taken from simulations of 1950-2010 with the GEOS chemistry climate model (CCM) [Pawson et al., 2008], and are calibrated (bias corrected) to the tropospheric concentrations specified by CMIP5 [Meinshausen et al., 2011]. Stratospheric $\mathrm{H}_{2} \mathrm{O}$ is also taken from the CCM. In both cases, GHGs and $\mathrm{H}_{2} \mathrm{O}$, fiveyear running averages are first computed to reduce the influence of interannual variability in the CCM fields. Ozone is specified from AC\&C/SPARC monthly averages [ftp-esg.ucllnl.org] from 1870-2005, and is converted to zonal means before interpolation onto GEOS-5 layers. For all seven gases, the relaxation fields have realistic latitudinal, vertical, and seasonal variations imposed on their specified trends. Two-day e-folding times allow the species contours to sufficiently follow planetary-scale potential vorticity deformations in the stratosphere.

Aerosols are computed using the Goddard Chemistry, Aerosol, Radiation, and Transport model (GOCART, Chin et al. 2002; Colarco et al. 2009) in GEOS-5. The GOCART module is run online within the GEOS-5 AGCM; that is, the aerosols and other tracers are radiatively interactive and transported consistently with the underlying hydrodynamics and physical parameterizations (e.g., moist convection and 
Table A1: List of Experiments.

\begin{tabular}{|l|l|l|l|l|}
\hline Experiments & Time period & Initial Conditions & SST and Sea Ice & $\begin{array}{l}\text { Radiative gases, ozone, } \\
\text { aerosols }\end{array}$ \\
\hline AMIP & $1980-2009$ & $\begin{array}{l}\text { MERRA: Jan 2, 9, and } \\
16^{\text {th }} \text { of 1980 }\end{array}$ & $\begin{array}{l}\text { Observed } \\
\text { (HadISST) }\end{array}$ & $\begin{array}{l}\text { “Observed”- see text } \\
\text { below }\end{array}$ \\
\hline Control & 20 years & MERRA: 1980 Jan 2 & $\begin{array}{l}\text { Repeating mean } \\
\text { annual cycle from } \\
\text { HadISST (1981- } \\
\text { 2005) }\end{array}$ & $\begin{array}{l}\text { gases are constant IPCC } \\
1992 \text { values (Table 2); } \\
\text { ozone is climatological } \\
(1981-2005) ; \\
\text { 2002 aerosols are }\end{array}$ \\
\hline Global Warming & 20 years & Same as control & $\begin{array}{l}\text { Same as control } \\
\text { plus uniform } 2^{\circ} \mathrm{C} \\
\text { increase over the } \\
\text { global oceans }\end{array}$ & Same as control \\
\hline Double $\mathrm{CO}_{2}$ & 20 years & Same as control & Same as control & $\begin{array}{l}\text { Same as control, but } \\
\text { double CO2 }\end{array}$ \\
\hline
\end{tabular}

turbulent mixing) of the model. GOCART treats the sources, sinks, and chemistry of dust, sulfate, sea salt, and black and organic carbon aerosols. Aerosol species are assumed to be external mixtures. Total mass of sulfate and hydrophobic and hydrophilic modes of carbonaceous aerosols are tracked, while for dust and sea salt the particle size distribution is explicitly resolved across 5 non-interacting size bins for each.

Both dust and sea salt formulations have wind-speed dependent emission functions, while sulfate and carbonaceous species have emissions principally from fossil fuel combustion, biomass burning, and biofuel consumption, with additional biogenic sources of organic carbon. Sulfate has additional chemical production from oxidation of SO2 and DMS, and we include a database of volcanic SO2 emissions and injection heights. For all aerosol species, optical properties are primarily from the commonly used OPAC data set (Hess et al. 1998). This framework also includes the representation of $\mathrm{CO}$ tracers, which have emissions from fossil fuel, biofuel, and biomass burning. The online CO processes in GEOS-5 derive from Bian et al. (2007), and include indirect production of $\mathrm{CO}$ from oxidation of natural and anthropogenic non-methane hydrocarbons, chemical production from methane $(\mathrm{CH} 4)$ oxidation, and losses through reaction with $\mathrm{OH}$. 
Table A2. Radiative gases from 1992 IPCC specifications

\begin{tabular}{|c|c|}
\hline Radiative gas & Amount \\
\hline $\mathrm{CO}_{2}$ & $3.56 \mathrm{E}-04$ \\
\hline $\mathrm{CH}_{4}$ & $1.714 \mathrm{E}-06$ \\
\hline $\mathrm{N}_{2} \mathrm{O}$ & $3.11 \mathrm{E}-07$ \\
\hline $\mathrm{CFC}_{11}$ & $2.68 \mathrm{E}-10$ \\
\hline $\mathrm{CFC}_{12}$ & $5.03 \mathrm{E}-10$ \\
\hline $\mathrm{CFC}_{113}$ & $8.20 \mathrm{E}-11$ \\
\hline $\mathrm{CFC}_{22}$ & $1.05 \mathrm{E}-10$ \\
\hline
\end{tabular}

\section{MERRA and Other Observations}

Our analysis is based in part on MERRA (Rienecker et al. 2011). MERRA is an atmospheric reanalysis that was produced with the Goddard Earth Observing System Data Assimilation System Version 5 (GEOS-5) documented in Rienecker et al. (2008), consisting of the GEOS-5 atmospheric model and the Grid-point Statistical Interpolation (GSI) analysis system, the latter being a system jointly developed by the GMAO and NOAA's National Centers for Environmental Prediction. The GEOS-5 assimilation system includes an incremental analysis update (IAU) procedure (Bloom et al. 1996) that slowly adjusts the model states toward the observed state. This has the benefit of minimizing any unrealistic spin down (or spin-up) of the water cycle. MERRA was run at a resolution of $12^{\circ}$ latitude $\times 2 / 3^{\circ}$ longitude with 72-levels extending to $0.01 \mathrm{hPa}$. More information about MERRA can be found at: http://gmao.gsfc.nasa.gov/research/merra/. This study uses standard monthly mean (JJA) and hourly output that is provided on 42 pressure levels at a horizontal resolution of $1^{\circ}$ latitude $\times 1.25^{\circ}$ longitude for the period 1979-2010. A more limited comparison is made with the NOAA Climate Forecast System Reanalysis (CFSR, Saha et al. 2010).

We also make use of various observations consisting of the daily and monthly mean Global Precipitation Climatology Project (GPCP) precipitation data (Adler et al. 2003), and the HadGHCN daily and monthly temperature data (Caesar et al. 2006). Some of the results are also based on daily NOAA Climate Prediction Center precipitation data (Xie et al. 2007). 


\section{Appendix B}

Some examples of fits to the GEV distribution

In order to estimate the 10-year return values of the maximum daily precipitation and the warmest days and warmest nights, we fit the maxima to the Generalized Extreme Value (GEV, Coles 2001) distribution:

where

$$
\frac{1}{\sigma} t(x)^{\xi+1} e^{-t(x)},
$$

$$
t(x)= \begin{cases}\left(1+\xi \frac{x-\mu}{\sigma}\right)^{-1 / \xi} & \text { if } \xi \neq 0 \\ e^{-(x-\mu) / \sigma} & \text { if } \xi=0\end{cases}
$$

and $\zeta, \mu$ and $\sigma$ represent that shape, location and scale of the distribution respectively. Examples of the fits are presented below.
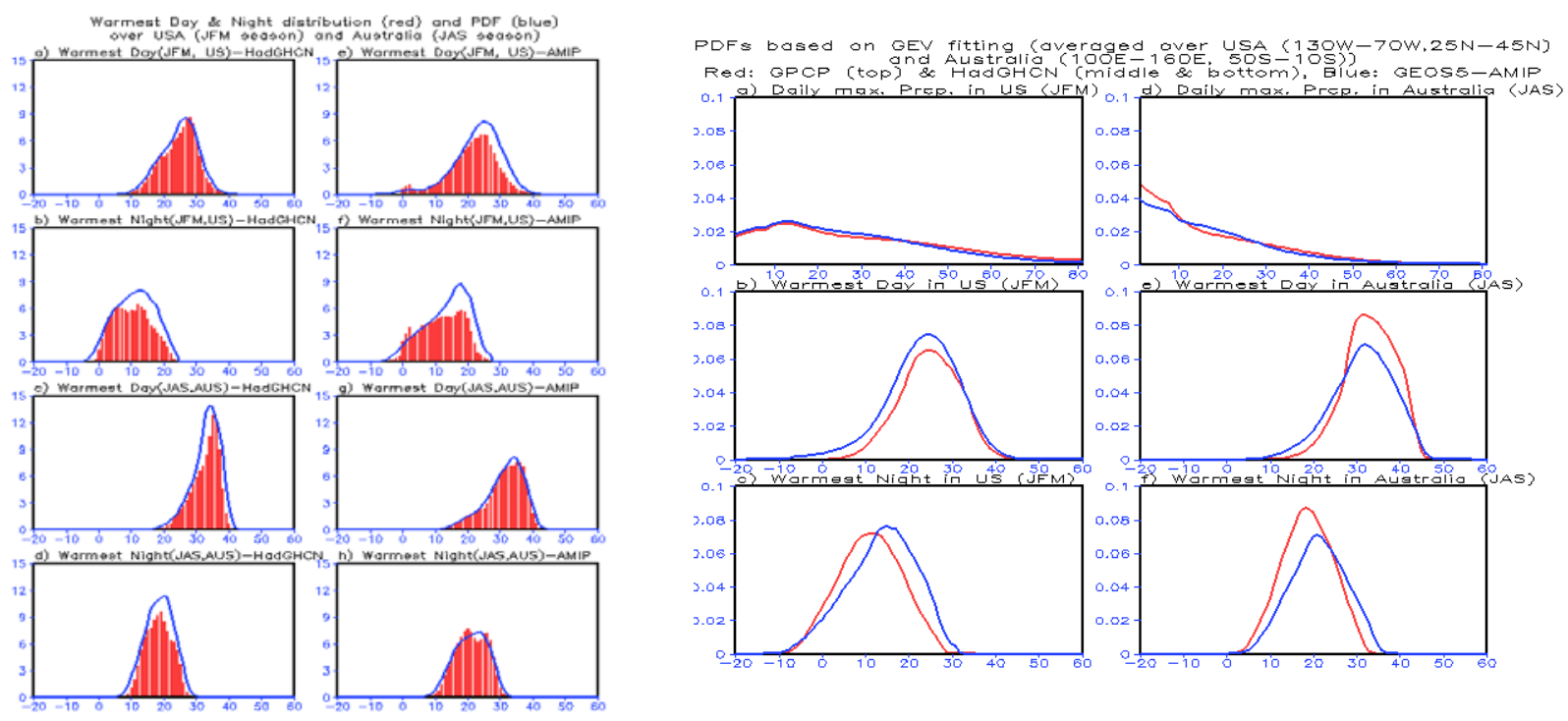

Figure B1: Left two columns of panels: Spatially averaged histograms with superimposed GEV fits from observations (left) and GEOS5-AMIP runs (right). Top: warmest days and nights temperature occurrences in percentage averaged over the US during JFM (red bars). Corresponding GEV fits are denoted by blue curves. Bottom: same but over Australia for JAS. X-axis denotes the actual temperature values whereas the $Y$-axis denotes the percentage values. Right set of panels: Direct comparisons of the spatially averaged GEV fits to the observations (red) and AMIP simulations (blue) for maximum daily precipitation (top panels), warmest day (middle panels), and warmest nights (lower panels). Spatial averaging was performed for the US (130W-70W, 25N-45N) for JFM on the left, and for Australia (100E-160E, 50S-10S) for JAS on the right. 


\section{References}

Adler, R.F., G.J. Huffman, A. Chang, R. Ferraro, P. Xie, J. Janowiak, B. Rudolf, U.

Schneider, S. Curtis, D. Bolvin, A. Gruber, J. Susskind, P. Arkin, 2003: The Version 2

Global Precipitation Climatology Project (GPCP) Monthly Precipitation Analysis (1979-

Present). J. Hydrometeor., 4,1147-1167.

Ashok, K., S. K. Behera, S. A. Rao, H. Weng, and T. Yamagata, 2007: El Niño Modoki and its possible teleconnection. J. Geophys. Res., 112, C11007, doi:10.1029/2006JC003798.

Alexander, L. V., et al. (2006), Global observed changes in daily climate extremes of temperature and precipitation, J. Geophys. Res., 111, D05109, doi:10.1029/ 2005JD006290.

Bacmeister, J.T., M.J. Suarez, and F.R. Robertson, 2006: Rain re-evaporation, boundarylayer/convection interactions and Pacific rainfall patterns in an AGCM, J. Atmos. Sci., 8, SRef-ID: 1607-7962/gra/EGU06-A-08925.

Bian, H., M. Chin, R. Kawa, B. Duncan, , A. Arellano Jr., and R. Kasibhatla, Uncertainty of global CO simulations constraint by biomass burning emissions. J. Geophys. Res., 112, D23308, doi:10.1029/2006JD008376, Dec. 2007

Bloom, S., L. Takacs, A. DaSilva, and D. Ledvina, 1996: Data assimilation using incremental analysis updates. Mon. Wea. Rev., 124, 1256-1271.

Bojariu, R. and Gimeno, L. (2003). The role of snow cover fluctuations in multiannual NAO persistence. Geophysical Research Letters 30(4): doi: 10.1029/2002GL015651. issn: 0094-8276.

Caesar, J., L. Alexander, and R. Vose (2006), Large-scale changes in observed daily maximum and minimum temperatures: Creation and analysis of a new gridded data set, J. Geophys. Res., 111, D05101, doi:10.1029/2005JD006280

CCSP SAP 1.3, 2008: Reanalysis of Historical Climate Data for Key Atmospheric Features. In: Reanalysis of Historical Climate Data for Key Atmospheric Features: Implications for Attribution of Causes of Observed Change. S. Schubert, P. Arkin, J. Carton, E. Kalnay, and R. Koster. A Report by the U.S. Climate Change Science Program and the Subcommittee on Global Change Research [Randall Dole, Martin Hoerling, and Siegfried Schubert (eds.)]. National Oceanic and Atmospheric Administration, National Climatic Data Center, Asheville, NC, pp. 11-46. 2008

CCSP SAP 3.3, 2008: Weather and Climate Extremes in a Changing Climate. Regions of Focus: North America, Hawaii, Caribbean, and U.S. Pacific Islands. A Report by the U.S. Climate Change Science Program and the Subcommittee on Global Change Research. [Thomas R. Karl, Gerald A. Meehl, Christopher D. Miller, Susan J. Hassol, 
Anne M. Waple, and William L. Murray (eds.)]. Department of Commerce, NOAA's National Climatic Data Center, Washington, D.C., USA, 164 pp.

Chang, E.K.M., and Y. Fu, 2002: Interdecadal variations in Northern Hemisphere winter storm track intensity. J. Clim., 15, 642-658.

Chang, Y., S. Schubert and M. Suarez, 2012: Attribution of the Extreme U.S. East Coast Snowstorm Activity of 2010, Accepted in J. Climate.

Chin, M., P. Ginoux, S. Kinne, O. Torres, B. N. Holben, B. N. Duncan, R. V. Martin, J. A. Logan, A. Higurashi, and T. Nakajima, 2002: Tropospheric aerosol optical thickness from the GOCART model and comparisons with satellite and sun photometer measurements, J. Atmos. Sci., 59, 461-483.

Colarco, P., A. da Silva, M. Chin and T. Diehl, 2009: Online simulations of global aerosol distributions in the NASA GEOS-4 model and comparisons to satellite and ground-based aerosol optical depth. J. Geophys. Res., 115, D14207, doi:10.1029/2009JD012820.

Coles, S., 2001: An Introduction to Statistical Modeling of Extreme Values, Springer, 208pp.

Collins, N., G. Theurich, C. DeLuca, M. Suarez, A. Trayanov, V. Balaji, P. Li, W. Yang, C. Hill, and A. da Silva, 2005: Design and implementation of components in the Earth System Modeling Framework. Int. J. High Perf. Comput. Appl., 19, 341-350, DOI: 10.1177/1094342005056120.

Compo, G. and P.D. Sardeshmukh, 2009: Oceanic Influences on recent continental warming. Clim. Dyn., 32, 333-342. DOI 10.1007/s00382-008-0448-9

Deser, C., A.S. Phillips, and M. A. Alexander, 2010: Twentieth century tropical sea surface temperature trends revisited. Geophys. Res. Let., 37, L10701, doi:10.1029/2010GL043321.

Ding, Q., E.J. Steig, D.S. Battisti, and J.M. Wallace, 2011: Influence of the tropics on the Southern Annular Mode. Submitted to J. Climate.

Easterling, D.R., + J. L. Evans, P. Ya. Groisman, T. R. Karl, K. E. Kunkel, and P. Ambenje, 2000: Observed Variability and Trends in Extreme Climate Events: A Brief Review. Bull. Amer. Meteor. Soc., 81, 417-425.

Feldstein, S.B., 2001: The recent trend and variance increase of the annular mode. J. Climate, 15, 88-94.

Fraedrich, K. and K. Muller, 1992: Climate Anomalies in Europe Associated with ENSO, International Journal of Climatology, 12, 25-31. 
Fu, Q., C. M. Johanson, J. M. Wallace, and T. Reichler (2006), Enhanced mid-latitude tropospheric warming in satellite measurements, Science, 312, 1179.

Fyfe, J.C, Boer, G.J., Flato, G.M. (1999), Climate studies-the Arctic and Antarctic Oscillations and their projected changes under global warming, Geophysical Research Letters, Vol. 26 (Issue 11), 1999, 1601-1604 (4).

Gates, W. L., 1992: AMIP: The Atmospheric Model Intercomparison Project. Bull. Amer. Meteor. Soc., 73, 1962-1970.

Gershunov, A. and T. Barnett, 1998: ENSO influence on intraseasonal extreme rainfall and temperature frequencies in the contiguous US: observations and Model Results. J. Climate, 11, 1575- 1586.

Ghil, M., and K. C. Mo, 1991: Intraseasonal oscillations in the global atmosphere. Part II: Southern Hemisphere. J. Atmos. Sci., 48, 480-490.

Gillett, N.P. F.W. Zwiers, A.J. Weaver, and P.A. Stott, 2003: Detection of human influence on sea-level pressure. Nature, Mar 20;422 (6929):292-4.

Gong, G., D. Entekhabi, J. Cohen, 2003: Modeled Northern Hemisphere Winter Climate Response to Realistic Siberian Snow Anomalies. J. Climate, 16, 3917 - 3931.

Held, I. M., and B. J. Soden (2006), Robust responses of the hydrological cycle to global warming, J. Clim., 19, 5686- 5699.

Hendon, H.H., M. C. Wheeler, and C. Zhang, 2007: Seasonal dependence of the MJOENSO relationship. J. Climate, 20, 531-543.

Hess, M., P.Koepke, and I.Schult, 1998: Optical properties of aerosols and clouds: The software package OPAC, Bull.Amer.Met.Soc., 79, 831-844.

Hoerling, Martin, Jon Eischeid, Judith Perlwitz, 2010: Regional Precipitation Trends: Distinguishing Natural Variability from Anthropogenic Forcing. J. Climate, 23, 21312145.

Hu, Z.-Z., A.Kumar, B. Jha, and B. Huang, 2011: An Analysis of Forced and Internal Variability in a Warmer Climate in CCSM3. J. Climate, early on-line release, 2011.

Hurrell, J. W., 1995: Decadal trends in the North Atlantic Oscillation: regional temperatures and precipitation. Science, 269, 676-679.

Hurrell, J. W., Influence of variations in extratropical wintertime teleconnections on Northern Hemisphere temperature, Geophys. Res. Lett., 23, 655-668, 1996. 
Hurrell, J.W., Kushnir, Y., Ottersen, G. \& Visbeck, M. (2003) The North Atlantic Oscillation: Climatic Significance and Environmental Impact. Geophysical Monograph Series. American Geophysical Union, Washington, DC.

Hurrell, J.W., et al., 2003: An overview of the North Atlantic Oscillation. In: The North Atlantic Oscillation: Climatic Significance and Environmental Impact [Hurrell, J.W., et al. (eds.)]. Geophysical Monograph 134, American Geophysical Union, Washington, DC, pp. 1-35.

Hurrell, J.W., et al., 2004: Twentieth century North Atlantic climate change. Pt I: Assessing determinism. Clim. Dyn., 23, 371-389.

Hurrell, J. W., and C. Deser, 2009: North Atlantic climate variability: The role of the North Atlantic Oscillation. J. Mar. Syst., 78, No. 1, 28-41, DOI:10.1016/ j.jmarsys.2008.11.026.

IPCC, 2007: Climate Change 2007: The Physical Science Basis. Contribution of Working Group I to the Fourth Assessment Report of the Intergovernmental Panel on Climate Change [Solomon, S., D. Qin, M. Manning, Z. Chen, M. Marquis, K.B. Averyt, M. Tignor and H.L. Miller (eds.)]. Cambridge University Press, Cambridge, United Kingdom and New York, NY, USA, 996 pp.

Jones, P. D., T. J. Osborn and K. R. Briffa, 2003: Pressure-Based Measures of the North Atlantic Oscillation (NAO): A Comparison and an Assesment of Changes in the Strength of the NAO and in its Influence on Surface Climate Parameters, Geophysical Monograph., 134, 51-62.

Kao, H.-Y. and J.-Y. Yu, 2009: Contrasting Eastern-Pacific and Central-Pacific types of ENSO. J. Climate, 22, 615-632.

Karoly, D. J., 1989: Southern Hemisphere circulation features associated with El NiñoSouthern Oscillation events. J. Climate, 2, 1239-1251.

Kenyon, J and G. C. Hegerl (2008): The Influence of ENSO, NAO and NPI on global temperature extremes. J. Climate 21, 3872-3889, doi 10.1175/2008JCLI2125

Kharin, Viatcheslav V., Francis W. Zwiers, Xuebin Zhang, 2004: Intercomparison of near surface temperature and precipitation extremes in AMIP-2 simulations. Journal of Climate, vol. 18, Issue 24, pp.5201-5223.

Kidson, J.W., 1988: Interannual variations in the Southern Hemisphere circulation. J. Climate, 1, 1177-1198.

Kidson, J., J. A. Renwick, and J. McGregor, 2009: Hemispheric-scale seasonality of the Southern Annular Mode and impacts on the climate of New Zealand. J. Climate, 22, 4759-4770. 
Koster, R.D., M.J. Suárez, A. Ducharne, M. Stieglitz, and P. Kumar, 2000: A catchmentbased approach to modeling land surface processes in a GCM, Part 1, Model Structure. J. Geophys. Res., 105, 24809- 24822.

Kumar, A., B. Jha, M. L’Heureux, 2010: Are tropical SST trends changing the global teleconnection during La Niña? GEOPHYSICAL RESEARCH LETTERS, VOL. 37, L12702, 6 PP., 2010, doi:10.1029/2010GL043394

Lefebvre, W., H. Goosse, R. Timmermann, and T. Fichefet, 2004: Influence of the Southern Annular Mode on the sea ice-ocean system. J.Geophys.Res., 109, C09005, doi:10.1029/2004JC002403.

Lim, Y.-K. and S. D. Schubert, 2011: The Impact of ENSO and the Arctic Oscillation on Winter Temperature Extremes in the Southeast United States. Geophys. Res. Let., 38, L15706, 5 PP., 2011, doi:10.1029/2011GL048283.

Lin, S.-J., 2004: A vertically Lagrangian finite-volume dynamical core for global models. Mon. Wea. Rev., 132, 2293-2307.

Linkin, M.E. and S. Nigam, 2008: The North Pacific Oscillation-West Pacific Teleconnection Pattern: Mature-Phase Structure and Winter Impacts. J. Climate, 21, 1979-1997.

Lu, J., G. A. Vecchi, and T. Reichler (2007), Expansion of the Hadley cell under global warming, Geophys. Res. Lett., 34, L06805, doi:10.1029/2006GL028443.

Mariotti, A., and A. Dell'Aquila, 2011: Decadal climate variability in the Mediterranean region: roles of large-scale forcings and regional processes. Climate Dyn., pub. on-line.

Marshall, G. J., 2003: Trends in the Southern Annular Mode from observations and reanalyses. J. Climate, 16, 4134-4143.

Meinshausen, M. and S. Smith, et al. "The RCP Greenhouse Gas Concentrations and their extension from 1765 to 2500" (in preparation), Climatic Change (Special Issue on RCPs) .

Mitas, C. M., and A. Clement (2006), Recent behavior of the Hadley cell and tropical thermodynamics in climate models and reanalyses, Geophys. Res. Lett., 33, L01810, doi:10.1029/2005GL024406

Mo, K., 2000: Relationships between Low-Frequency Variability in the Southern Hemisphere and Sea Surface Temperature Anomalies. J. Climate, 13, 3599 - 3610.

Moorthi, S., and M.J. Suarez, 1992: Relaxed Arakawa-Schubert, A Parameterization of Moist Convection for General-Circulation Models. Mon. Wea. Rev. 120, 978-1002. 
Morgenstern, O. and coauthors, 2010: Anthropogenic forcing of the Northern Annular Mode in CCMVal-2 models. JOURNAL OF GEOPHYSICAL RESEARCH, VOL. 115, D00M03, 15 PP., 2010 doi:10.1029/2009JD013347.

Newman, M., S.-I. Shin, and M. A. Alexander, 2011: Natural Variation in ENSO Flavors. Submitted to GRL, 2011.

Pawson, S., R. S. Stolarski, A. R. Douglass, P. A. Newman, J. E. Nielsen, S. M. Frith, and M. L. Gupta (2008), Goddard Earth Observing System chemistry-climate model simulations of stratospheric ozone-temperature coupling between 1950 and 2005, J. Geophys. Res., 113, D12103, doi:10.1029/2007JD009511.

Quadrelli, R., and J.M. Wallace, 2004: A simplified linear framework for interpreting patterns of Northern Hemisphere wintertime climate variability. J. Clim., 17, 3728-3744.

Raible CC, Stocker TF, Yoshimori M, Renold M, Beyerle U, Casty C, Luterbacher J (2005): Northern Hemispheric trends of pressure indices and atmospheric circulation patterns in observations, reconstructions, and coupled GCM simulations. J. Climate 18:3968-3982

Reason, C. J. C., and M. Rouault, 2005: Links between the Antarctic Oscillation and winter rainfall over western South Africa. Geophys. Res. Lett., 32, L07705, doi:10.1029/2005GL022419.

Richman M.B., 1986. Rotation of principal components. J. Climatol., 6, 293-335.

Rienecker, M. M., and Coauthors, 2008: The GEOS-5 Data Assimilation System Documentation of Versions 5.0.1 and 5.1.0, and 5.2.0. NASA Technical Report Series on Global Modeling and Data Assimilation, NASA/TM-2008-104606, Vol. 27, 92 pp.

Rienecker, M. M., and Coauthors, 2011: MERRA - NASA's Modern-Era Retrospective Analysis for Research and Applications. Journal of Climate, e-View doi: 10.1175/JCLID-11-00015.1

Saha S., and Coauthors, 2010: The NCEP Climate Forecast System Reanalysis. Bull. Amer. Meteor. Soc., 9, 1015-1057.

Scaife, A. A., C. K. Folland, L. V. Alexander, A. Moberg, and J. R. Knight, 2008: European climate extremes and the North Atlantic Oscillation. J. Climate, 21, 72-83

Schubert, S. D., Y. Chang, M. J. Suarez, and P. J. Pegion. ENSO and Wintertime Extreme Precipitation Events Over the Contiguous United States. J. Climate, 21, 22-39, 2008.

Seager, R., M. F. Ting, I. Held, Y. Kushnir, J. Lu, G. Vecchi, H. P. Huang, N. Harnik, A. Leetmaa, N. C. Lau, C. H. Li, J. Velez(Nakamura) and N. Naik, 2007: Model projections 
of an imminent transition to a more arid climate in southwestern North America. Science, 316(5828): 1181-1184

Silvestri, G. E., and C. S. Vera, 2003: Antarctic Oscillation signal on precipitation anomalies over southeastern South America. Geophys. Res. Lett., 30, 2115, doi:10.1029/2003GL018277.

Thompson, D. W. J., and J. M. Wallace, 2000: Annular modes in the extratropical circulation. Part I: Month-to-month variability. J. Climate, 13, 1000-1016.

Thompson, D.W.J.J.M. Wallace, and G. C. Hegerl, 2000: Annular modes in the extratropical circulation: Part II: Trends. J. Climate, 13, 1018-1036.

Thompson, D.W.J., and J.M. Wallace, 2001: Regional Climate Impacts of the Northern Hemisphere Annular Mode. Science, 293, 85-89.

Thompson, D.W.J. and Solomon, S. 2002. Interpretation of recent Southern Hemisphere climate change. Science , 296: 895-899.

Trenberth, K.E., D.P. Stepaniak, and L. Smith, 2005: Interannual variability of the patterns of atmospheric mass distribution. J. Clim., 18, 2812-2825.

Turner, J., 2004: The El Niño-Southern Oscillation and Antarctica. Int. J. Climatol., 24, $1-31$.

Xie, P., A. Yatagai, M. Chen, T. Hayasaka, Y. Fukushima, C. Liu, and S. Yang, 2007: A gauge-based analysis of daily precipitation over East Asia, J. Hydrometeorol., 8, 607626.

Yeh, S-W. et al. (2009), El Niño in a changing climate, Nature, 461, 511-514. 